\title{
Becoming a more attractive supplier by managing references - The case of small and medium-sized enterprises in a digitally enhanced business environment
}

\section{Introduction}

Small is beautiful too (Schumacher, 2011): while a large client may well generate considerable turnover, creating a balanced portfolio of customer firms that includes small and medium-sized enterprises (SMEs) helps to manage risks and to establish a more innovative environment for value creation (De Mattos, Burgess, \& Shaw, 2013). To achieve these benefits, suppliers need to better understand how they can make themselves attractive in the eyes of SME customers. Understandably, due to resource limitations, SME customers tend to be more careful about selecting suppliers in comparison to large firms (Narula, 2004). Moving these considerations to an increasingly digitalized business environment characterized by information overload adds further layers of complexity (Bi, Liu, \& Usman, 2017). Although effective reference management via corporate online references and Word of Mouth (WOM) recommendations is of great importance, in that they enable firms to communicate key qualities and competencies and to convey attractiveness (Helm \& Salminen, 2010), our current understanding is limited as to how attractiveness may be established and attained in the eyes of SME managers (Mortensen, 2012).

Corporate online references such as client testimonials and logos represent forms of communication that are mutually agreed between the supplier who publishes them on their website, and the previous clients who provided the reference in the first place. As references appear on corporate websites, they become publicly available for all interested stakeholders, including potential future clients who wish to gather more information about the particular supplier during the partner pre-selection phase. It is important to note that in contrast with WOM recommendations, corporate online references are almost always positive, given that the supplier has full control over what is shared on their corporate website.

The literature on online references is increasing yet remains more widely explored in B2C (Kumar, Petersen, \& Leone, 2010; Pansari \& Kumar, 2017; Schmitt, Skiera, \& Van den Bulte, 2011; Verhoef, Franses, \& Hoekstra, 2002) rather than B2B contexts (Terho \& Jalkala, 2017). Some of the existing B2B work takes a conceptual approach to exploring the organizational 
value of references (Helm \& Salminen, 2010), while others pursue an in-depth understanding of the narratives of B2B online references (Aarikka-Stenroos, Sandberg, \& Lehtimäki, 2014; Terho \& Jalkala, 2017). An important distinction needs to be made concerning terminology. In particular, the two expressions 'references' and 'referrals' are often used interchangeably in the extant literature. Within the B2C literature, 'customer referrals' (Kumar et al., 2010; Verhoef et al., 2002) or 'consumer referrals' are common (Koch \& Benlian, 2015). Within the B2B context, however, scholars recommend avoiding the word 'referral' when talking about references, as they consider this term to be misleading by placing too much emphasis on the person providing the reference (Aarikka-Stenroos, 2011). In order to maintain consistency and conceptual clarity, the term 'reference' will be used throughout the present paper.

Research in the field of $\mathrm{B} 2 \mathrm{~B}$ online references has reached a stage of conceptual maturity to warrant a comprehensive exploration concerning the effectiveness of different B2B reference types. Nonetheless, although effective reference management practices are particularly advantageous during the initial stages of supplier selection (i.e. pre-selection), existing research offers no guidance about which type of corporate online referencing may work best in different SME contexts.

Against this background, the present study addresses the above gaps and thus contributes to the academic discourse on B2B referencing and, more specifically, on the mechanisms by which corporate online references, WOM and the customer firm's size influence supplier pre-selection in different ways. Firstly, we explore the impact of the customer firm's size on perceived reference effectiveness, and study whether companies of different sizes may represent distinct preferences. Secondly, we differentiate WOM recommendations from corporate online references in line with earlier work (Jalkala \& Salminen, 2009; Reimer \& Benkenstein, 2016), attempting to single out their unique influence on partnering attractiveness evaluations and subsequent behavioral intentions, above and beyond other referencing tools. Finally, we distinguish amongst different reference types by the extent of their information elaboration (elaboration in this study is defined as the overall amount of reference information available), and in particular explore whether more elaborate references may be more effective when compared to less elaborate references. This is innovative as it empowers reference information 
elaboration to become an empirically studied factor of attractiveness, using a comparative approach.

The intention to initiate the business relationship serves as a proxy for partnering attractiveness, which in consumer settings is analogous to purchase intention (Baker, Donthu, \& Kumar, 2016). It is important to note that this study focuses on this early 'mating' stage of customer-supplier relationships, instead of attractiveness in more mature relationships. While the linearity of traditional relationship development models is questionable, the identification of different relationship stages is an important contribution. For instance, Dwyer, Schurr, and Oh (1987), Ford (1980) and Wilson (1995) distinguish between early and mature developmental stages of business relationships. A common pattern emerges across these frameworks, with respect to the underlying notion of attractiveness that is embedded in their argumentation. In particular, they all consider the time-period when relationships are born, assigning it with a slightly different label; referring to it as the stage of awareness (Dwyer et al., 1987), the prerelationship stage (Ford, 1980), or the partner selection (Wilson, 1995). Wilson (1995) goes on to explaining how certain conditions play a vital role in particular stages of the relationship. More specifically, the development of social bonds tends to be a characteristic of the partner selection and early relational phases of relationship development, whereas adaptations and the establishment of cooperative practices tend to emerge during subsequent and more mature stages.

In fact, the type and level of relationship-specific investments tend to change over the course of the relationship development process, as demonstrated by Claycomb and Frankwick (2010). Communication is a good example for this, as one of its aims is to decrease the customer's uncertainty about whether to further develop the relationship with the supplier, and if so, how to do so. Mandják, Szalkai, Neumann-Bódi, Magyar, and Simon (2015) posit that while the consideration of economic incentives is not entirely absent, the early stages of attraction tend to capture information-seeking activities that help organizations obtain sufficient information concerning the firms to which they are attracted, and with whom they (customers and suppliers alike) are likely to initiate a relationship. Consequently, the intention to initiate the relationship indicates partnering attractiveness, specific to the pre-relationship stage, which is where references play a particularly important role. 


\section{Theoretical background}

Establishing successful business relationships are advantageous for companies, yet given the time, effort and resources required, firms need to be selective in their choice of partners (Hald, 2012; Hüttinger, Schiele, \& Schröer, 2014; Schiele, Calvi, \& Gibbert, 2012; Tanskanen \& Aminoff, 2015). There is an increasing body of work that explores factors that may facilitate rather than hinder the process of B2B value exchange, in which partner selection and subsequently network establishment serve as key elements (Albadvi \& Hosseini, 2011; Hada, Grewal, Lilien, \& Gary, 2013; Hüttinger, Schiele, \& Veldman, 2012; Ramsay \& Wagner, 2009). B2B references are particularly important in that they are often considered among the key antecedents of overall firm attractiveness (Hüttinger et al., 2014), specific to the pre-relationship stage.

Using references from previous customers can increase the partnering attractiveness of the supplier in the eyes of future potential clients, especially during the supplier pre-selection phase. In the current section, we discuss some vital characteristics of the customer vis-à-vis firm size that are relevant to attractiveness. Conceptually, supplier attractiveness has been shown to serve as a vital success factor in business relationships (Olsen \& Ellram, 1997), and to play an essential part in the portfolio strategy because customer firms evaluate and target certain suppliers for their resource allocation (Zolkiewski \& Turnbull, 2002). The drivers of supplier attractiveness go beyond financial factors, and may include strategic, cultural, organizational and technological considerations (Olsen \& Ellram, 1997), along with value, trust and dependence (Hald, Cordón, \& Vollmann, 2009).

Attraction can be regarded as a relational bond (Halinen, 2001) that encourages partners to mobilize time and pecuniary resources (Ellegaard \& Ritter, 2006), and to become more loyal (Mortensen, Freytag, \& Arlbjørn, 2008). Mirroring the theoretical stance of the relational nature of customer attractiveness (Ellegaard, 2012; Hüttinger et al., 2012; Mortensen \& Arlbjorn, 2012; Tóth, Henneberg, \& Naudé, 2015), supplier attractiveness can be defined as the attitude towards the supplier that incorporates future expectations, and - when applicable - previous experiences with them, in turn encouraging potential or actual partners to develop, maintain and enhance the relationship with the supplier through making relationship-specific investments. Relationship- 
specific investments are not restricted to pecuniary investments, but instead can also include nonfinancial investments such as time, dedicated attention, and the allocation of skilled employees.

In the following section, we turn to considering drivers of supplier attractiveness, paying special attention to referencing in general, and corporate online referencing in particular. Within this context, we take into account that the use of corporate online referencing is often triggered by a personal (WOM) recommendation. Consequently, we discuss the nature of both constructs, i.e. corporate online referencing and WOM recommendations, along with their characteristics and operationalizability.

\subsection{Firm size and attractiveness in supplier pre-selection}

Supplier pre-selection can be viewed as a discovery process during which alternatives are explored and contemplated. In professional settings - typically in large company contexts - this is often followed by ranking and contextualization that ultimately lead to the decision about whom the company finds attractive to work with (de Boer, Labro, \& Morlacchi, 2001). Size has been identified as an important differentiating factor in a range of SME-based studies, and generally has been attracting increasing attention from scholars. While the supplier's partnering attractiveness can be positively influenced by using offline and face-to-face resources such as conferences, events, and association memberships (Nollet, Rebolledo, \& Popel, 2012), online tools and online media management, including website appeal and social network usage become critical for business success (Srinivasan, 2004).

Pressey, Winklhofer, and Tzokas (2009) highlight that SMEs are less inclined to employ a standard form or certification document pertaining to supplier evaluation, and tend to put more emphasis on the overall network aspect. Corporate websites present a vast amount of material concerning the supplier - often incorporating information about previous partners and prior working relationships, and reviewing them in great detail requires substantial effort on behalf of potential customers (Dobler, Burt, \& Starling, 2003). Furthermore, the perceived value prospective customers anticipate to gain when entering a relationship with the supplier is highly subjective (Hald et al., 2009), yet SME buyers appear to put more emphasis on supplier monitoring as they have less resources to allocate towards gradual supplier development (Pressey et al., 2009). Consequently, suppliers are encouraged to carefully consider the type and amount 
of information they share about themselves (Jalkala \& Salminen, 2009), which applies to reference information as well.

In order to address the important role of self-representation, firms can consider different drivers of organizational attractiveness. Tanskanen and Aminoff (2015) identified four primary categories, including economic factors (i.e. size and growth); behavioral attributes (i.e. communication, trust and commitment); resources (i.e. capabilities, competencies and resources); and bridging activities (i.e. access to partners and networks). Firm size is discussed as a particularly relevant contextual antecedent for reference utilization (Salminen \& Möller, 2006) and for the development of loyalty in customer-supplier relationships (Visentin \& Scarpi, 2012), yet - as indicated above - relatively little is known about effective reference management practices in SME settings.

Managing firm attractiveness, and as part of this managing references, are complex strategic endeavors, yet they are necessary to ensure effective buyer-supplier relationships and in turn attain a competitive position in the market (Adams, Khoja, \& Kauffman, 2012). In aiming for these goals, small firms are likely to face additional challenges - at least compared to mediumsized or larger firms - in securing internal managerial resources to implement successful strategies (Ramsay, 2001). In his work exploring small firms' innovation contributions, Brush (2014) finds that adaptation and information sharing, together with trustworthiness, personal relationships and goal congruence are key determinants of innovation contribution. Furthermore, the author concludes based on conducting interviews with managers in small innovative manufacturing firms that personal relationships are often critical in gaining support and "ensuring an effective working relationship" (pp. 17).

In their study exploring the entrepreneurial orientation and performance in sports firms, Núñez-Pomar, Prado-Gascó, Añó Sanz, Crespo Hervás, and Calabuig Moreno (2016) find entrepreneurial orientation to be a sufficient condition for performance in small firms, but less so in large ones. Similar conclusions are drawn on the basis of the research conducted by VerdúJover, Lloréns-Montes, and García-Morales (2006), exploring different practices of flexibility within small and large firms, in the case of buyers and suppliers alike. The authors find greater flexibility fit, referring to the co-alignment between actual and required flexibility, to have a more pronounced impact on business performance in the case of small versus large firms. 
Furthermore, within the agro-food industry sector, Redondo and Fierro (2007) conclude that company size influences the temporal orientation of buyer-supplier relationships. More specifically, trust was found to be a fundamental factor in initiating a relationship with a supplier, as well as determining the subsequent level of satisfaction with the relationship, which was not the case for large firms. Similarly, commitment emerged as a significant factor in the temporal relational orientation for small but not for large firms. Finally, Hätönen and Ruokonen (2010) demonstrate that within the ICT industry, small size can be seen not as a weakness, but rather "as a potential advantage in the form of increased responsiveness, flexibility, and service level compared to their large rivals" (pp. 159).

Turning to the literature on supplier selection, an important gap can be observed. More specifically, existing studies largely neglect the heterogeneity of SMEs (Morrissey \& Pittaway, 2004), warranting research that embraces the distinction between small and medium-sized companies. Pursuing such research would be advantageous given the established differences with respect to uncertainty management as a function of size (Belt, Harkonen, Mottonen, KropsuVehkapera, \& Haapasalo, 2010). While medium-sized firms are generally perceived as more established with more clearly defined organizational structures, small companies share a range of characteristics with entrepreneurial ventures (Ellegaard, 2006). In fact, research demonstrates that large firms tend to use formal processes to evaluate suppliers, while small organizations tend to employ informal methods (Pearson \& Ellram, 1995).

In the pursuit of definitional clarity, smaller and larger SMEs should be differentiated. Several scholarly contributions distinguish small companies exclusively by the number of employees (Freel, 2000; Quayle, 2002) - although the employee number threshold varies across different studies. The majority of scholarly work assumes employee numbers below 50 versus 50-250 as a category threshold for small- as opposed to medium-sized enterprises (Cepeda \& Vera, 2007; Felzensztein, Brodt, \& Gimmon, 2014; Janeiro, Proença, \& Gonçalves, 2013; Rodríguez, Pérez, \& Gutiérrez, 2008). Additional features that differentiate small SMEs from large ones include the accumulation and placement of control over key decisions in the hands of the individual owner or a small group of people (Dollinger \& Kolchin, 1986); the consideration of multiple factors during selection decisions beyond profit-maximization (Morrissey \& 
Pittaway, 2004); and the fact that small companies typically do not have professional purchasing practices (Gadde \& Hakansson, 2001).

Common disadvantages entail the limited nature of formal processes, higher dependence (Lin \& Lin, 2016), greater focus on day-to-day issues as opposed to long-term strategic goals, and importantly, relative lack of resources (Adams et al., 2012; Duhan, Levy, \& Powell, 2001; M. Levy \& Powell, 1999). Consequently, the decision-making processes undertaken by small companies in 'business mating' engagements (Wilkinson, Young, \& Freytag, 2005) are likely to differ from those of medium-sized or large firms, where organizational structures are more formalized (Chollet, Géraudel, \& Mothe, 2014). Similarly, as the availability of resources assigned to marketing within SME contexts is limited, the need for cost-efficient marketing communication tools is paramount (Adams et al., 2012; Duhan et al., 2001). SMEs - and especially the smaller firms - need to deal with information overload, more pertinent time constraints and limited number of employees available to assist with tasks in the value creation process (Herrera-Echeverri, Geleilate, Gaitan-Riaño, Haar, \& Soto-Echeverry, 2016). Given these constraints, using references in supplier selection, along with other relevant practices such as written and verbal references, deserve more detailed investigation.

\subsection{Referencing as driver of supplier attractiveness in the pre-selection phase}

In a digitally enhanced business environment, corporate online references constitute an integral part of the supplier's online presence and in turn impact its attractiveness towards potential partners. References are predominantly positive statements provided by external parties in business relationships that can be expressed verbally and/or through symbols (M. Johnson \& Zinkhan, 1998; Waller, Cusick, Matheson, \& Miller, 2001), or can take the form of written references (Jalkala \& Salminen, 2009). They are created within specific business relationship structures and thus are not transferrable. There is always a Sender (typically the Reference Customer), a Receiver (typically the Supplier) and a Third-Party Actor(s) at whom the reference is aimed, i.e. the Potential Customer. The Reference Customer possesses a history of established and direct relationship with the Receiver supplier, which may impact the initiation processes between Third-Party Actors and the Receiver supplier. In addition to considerations associated with performance, engagement, and relationship sustainability (Baxter, 2012; Nollet et al., 2012), 
attractiveness has been described as a key determinant of relational and network-focused endeavors (Fiocca, 1982; Makkonen, Vuori, \& Puranen, 2016; Mortensen \& Arlbjorn, 2012; Pardo, Henneberg, Mouzas, \& Naudë, 2006; Pulles, Schiele, Veldman, \& Hüttinger, 2016), especially given its role in initiating resource mobilization in B2B settings (Mortensen, 2012; Mortensen et al., 2008).

Although our understanding of the links between reference-driven attractiveness management and business networks is limited, references can be used to influence networks and thus have an important contributing potential to network development. From a business network perspective (Snehota \& Håkansson, 1995), the assortment of customer references that appears on a corporate website can be viewed as a set of activity links posited as the supplier's resource collection. When potential clients initiate a relationship with the supplier that is triggered by the reference, a web of actors is created that ultimately contributes to the growth of the extended business network. In this sense, reference relationships can entail constructive network effects (Anderson, Håkansson, \& Johanson, 1994). As opposed to creating value within the dyad as a direct function (Walter, Ritter, \& Gemüden, 2001), this network effect of referencing is an indirect one, especially regarding its market-signaling ability (Möller \& Törrönen, 2003). Signaling (for example, through referencing) influences the firm's network identity in terms of its attractiveness as an exchange partner in the greater business network (Anderson et al., 1994).

\subsection{WOM recommendations and corporate online references}

Through WOM recommendations, customers spread the word about a collaboration or offering of a firm to their actual and potential partners and stakeholders, setting in motion a chain of communication that could spread through an entire network (Mason, 2008). WOM recommendations differ from other references: while the supplier chooses which references appear on their website, they cannot control whether and how they receive WOM. While written references are 'formalized' in that they are typically made available online as part of corporate websites (Jalkala \& Salminen, 2010) or brochures, WOM recommendations are perishable and specific to an inter-personal context at a given time. Consequently, online reference types such as logos and client testimonials make operationalizability more manageable over WOM recommendations. Besides the variety of communication valance, WOM is beneficial given its 
potential to reach a wide range of audience that would welcome in-person recommendations over other alternative forms of online communication.

Within the B2B referencing literature, different reference tools are discussed, for example, testimonials, case studies (Jalkala \& Salminen, 2010) and logos (Waller et al., 2001). Logos belong to the category of signals and symbols (Herbig, 1994) and are used predominantly for legitimization purposes; similarly to signs and symbols of awards (Bridwell-Mitchell \& Mezias, 2012; Rao, 1994). In their role as references, they represent symbolic actions (Zott \& Huy, 2007) and serve a passive awareness building function (Aarikka-Stenroos, 2011). Using clients' logos can be compared to stamps or (digital) footprints that confirm the existence of a current or past business relationship. Logos are essentially a form of borrowed equity that embody impersonal artefacts that convey 'open to all' reference information. Logos are quite rigid in that they leave no room for flexibility or adjustment to be made by the Receiver. They often appear among a list of customer logos to present a track record of the firm's partnership network (Payne, Ballantyne, \& Christopher, 2005).

An ample number of endorsers have been shown to be advantageous as they signal long-term trustworthiness and a history of good performance, which in turn help to build awareness (Aarikka-Stenroos, 2011). Presenting a track record of references from customers can be more persuasive than any other credentials (Waller et al. (2001). Logos are important in that they encompass certain intrinsic dimensions related to organizational achievements and signal 'solid competence' (Zott \& Huy, 2007). These symbolic acts are especially relevant for SMEs in the case of complex services, where such semi-physical and tangible elements may compensate for the intangibility deficit that is generally inherent in service engagements (Thrassou \& Vrontis, 2006). Although more extensive information elaboration may occur in the future, the information elaboration of logos is rather limited and restricted to the identification of the client company and the confirmation that there is - or has been - a relationship between the reference customers and the potential supplier.

Testimonials comprise written stories and descriptions that concern personal or corporatelevel experiences (Braverman, 2008). In a typical testimonial, an actor tells Third-Party Actors about a personal experience and directly or indirectly encourages the audience to follow the actor's example, or in other words try the product or service. Jalkala and Salminen (2010) 
explored characteristic discourses in testimonials, including benefits, relationship commitment and expertise. Keywords such as 'collaboration', 'great performance' and 'timely delivery' were identified as contextualization cues intended to invoke an intention to establish new relationships (Levinson, 2003). In comparison to logos, such embedded interactional move towards a hypothetical group of Third-Party Actors expects more elaborated reference information and requires greater commitment and input on behalf of the partner. Case studies represent a longer and more extended version of testimonials that some treat as a separate category (Helm \& Salminen, 2010), while they can also be considered under the general umbrella of textual customer references (Jalkala \& Salminen, 2009).

One way to differentiate between references is to consider the amount of information typically provided in each reference type. References reveal different levels of information about potential suppliers and their relationship with the reference customers, consequently supporting the navigation through the precarious nature of organizational partner selection. The degree of information elaboration is relevant given the variations that characterize customers' willingness to invest cognitive effort (S. Levy \& Nebenzahl, 2008). There is, however, no agreement on whether more reference information elaboration is always desirable. More elaboration can indeed decrease uncertainty among choices (Ellis and Shpielberg (2003). Keeping it 'sweet and short', however, as a result of incorporating less information elaboration, requires less cognitive effort (i.e. attention and considerations) from the customer (Yoganathan, Osburg, \& Akhtar, 2018) and can therefore save time, which - as mentioned above - in the case of SMEs can be a particularly crucial consideration when facing resource scarcity.

In conclusion, we know from the available literature that customer referencing is an important driver of supplier attractiveness during the supplier pre-selection process. It is also apparent that in a digitally enhanced environment, corporate online references play an increasingly important role besides WOM. Different forms of corporate online references can be differentiated on the basis of the extent of their information elaboration. For instance, when considering two distinct illustrative examples of corporate online references, such as client testimonials and partner logos, we find that client testimonials provide more detailed textual information about a previous collaboration than do partner logos. Consequently, focusing on client testimonials and partner logos appears to be a reasonable direction for further exploration. 
Furthermore, as large customers tend to have more formalized supplier selection processes, the impact of referencing among small- and medium-sized customers may be particularly insightful in the context of partnering attractiveness. Addressing the SME perspective seems at present to be a gap in the organizational attractiveness literature, with particular attention to the differences between small and medium-sized customers. Another identified gap concerns the intertwined nature of WOM and corporate online referencing that we are keen to address in terms of their impact on supplier attractiveness. Given the substantial differences between them (whether visual or verbal in nature), however, in the present work we consider logos and testimonials as separate from WOM recommendations.

\section{Research design}

Addressing the gaps in the literature regarding reference management, the present study aims to investigate the influence of the customer firm's size, WOM, and different types of corporate online references on the intention to initiate a relationship with a given supplier. To achieve this, we employed a mixed-methods design, incorporating a qualitative exploratory phase followed by an experiment. In the qualitatively oriented Stage I, we conducted 10 in-depth interviews and a separate focus group with $12 \mathrm{SME}$ managers. The aim of this phase was two-fold: on the one hand, to solicit in-depth information and reflections regarding SME managers' perceptions about B2B references, and on the other hand to assist with certain context-specific decisions regarding the experimental design. During our sampling, it was important to recruit participants with prior experience and expertise in partner selection processes. Prior to launching the experimental phase, a pilot was conducted to test and confirm the clarity of written and visual content. In Stage II, an online experiment was conducted with 165 SME managers to assess preferential differences between small and large SMEs in terms of corporate online references (focusing on the extent to which these references are elaborated) and WOM.

Multiple factors act jointly when it comes to reference effectiveness. We distinguish between small and large SMEs (note: the terms 'large SMEs' and 'medium-sized firms' are used interchangeably in the literature) in terms of the impact of the customer firm's size on reference effectiveness, as approximated by intentions to initiate a relationship with the supplier. Also, even though WOM recommendations should be treated as a separate category from logos and testimonials, as we argued earlier, they should be explored in conjunction with online reference 
forms in terms of their impact. WOM recommendations are unique as they provide first-hand confirmation of competence and established relational success, often building on feedback from customers who essentially serve as spokespersons for the company (Srivastava \& Sharma, 2017).

Among corporate online references, logos are the simplest form of reference that do not entail extensive information elaboration and require minimal input from the reference customer beyond the establishment of their relationship history. Testimonials provide a greater extent of information elaboration in comparison to logos. Of the written textual references, testimonials were selected over case studies, given their similarities in terms of reference form, and their considerable ease and simplicity of presentation in an online questionnaire format.

Our study is unique in that it explores how firm size interacts with other factors such as preferences regarding the presence of a WOM recommendation and the amount of desirable written reference elaboration. All these outlined factors contribute to the formation of new customer-supplier relationships and consequently to how the network evolves. The interaction of these factors is acknowledged in the research design. In collecting, managing and analyzing the data, the ethical guidelines of the lead author's university were followed. More specifically, all participants were ensured of full confidentiality and anonymity throughout the entire research

process. Data were collected during the course of two years between the beginning of 2016 and end of 2017.

\subsection{Stage I - Qualitative phase - Sampling and procedures}

The qualitative phase involved 22 SME managers (Table 1) and relied on the additional assistance of two graphic designers and six SME managers for purposes of stimuli development. Participants were recruited from the primary investigator's greater university network. A number of conditions had to be fulfilled in order to qualify for participating in the current study. More specifically, managers needed to be in an influencer or decision-making role concerning interorganizational partnerships; and had to possess prior experience with at least one partner selection process. These filter questions were verified prior to the interview, and if a particular interviewee did not have sufficient experience, managerial role or substantial understanding concerning business relationship management, the interview did not take place. The same criteria applied for the organization of the focus groups as well. By implementing a two-step sampling 
procedure using firmographics (here capturing firm size and industry background) and the identification of key informants within the chosen firms (i.e. based on relevant experience and influence), we follow a common practice in B2B marketing (Anaza, Kemp, Briggs, \& Borders, 2019; J. L. Johnson, Martin, \& Saini, 2012; W.-L. Wang, Malthouse, Calder, \& Uzunoglu, 2017). SMEs participating in the qualitative phase were all based in the North-West and Midlands of England.

\subsubsection{Interviews}

10 in-depth interviews were conducted with managers working at SMEs in the United Kingdom (four from manufacturing, and six from professional services), representing a range of industries such as IT, consultancy, packaging, architectural design and aerospace. The primary aim of the interviews was to gather insights concerning ways in which participants may go about selecting suppliers and perceive the potential influence of corporate online references on partnering attractiveness throughout the supplier pre-selection process. Interviews were semistructured, with a duration ranging between 40 to 60 minutes. All interviews were audiorecorded and transcribed with the help of professional transcription services that resulted in altogether 154 pages of transcripts.

Initial guidelines for the interview protocol were formulated building on the above literature review, with some questions targeting the potential role of different reference types (logos, testimonials) and firm size, and whether WOM was present or not. At the same time, participants were encouraged to elaborate on their own partner-selection specific experiences, reflecting upon actual scenarios as well as hypothetical cases (Gremler, 2004). In preparation for the experimental phase, towards the end of the interviews, managers were shown a set of visual props and stimuli (logos, firm names and general visual content) to gather their reactions and feedback

The transcribed interviews were coded by the members of the research team. The analysis

followed primarily a thematic approach (Braun \& Clarke, 2006) with the use of some open coding (Bryman \& Burgess, 1994) as well. The underlying logic of the interview structure followed a 'funnel' approach (Patton, 2002) starting from the 'big picture' of attractiveness perceptions, towards partner selection practices and then inquiries about the use of references, 
with special regards to WOM and available online information. This logic has informed the tabulation as well: starting from a more contextual understanding related to attractiveness in general, moving gradually towards specificities.

Within the scope of supplier pre-selection and selection practices, themes included - but were not limited to - (1) attractiveness considerations, (2) perceptions regarding different reference applications; (3) the role of WOM in partner selection, (4) the use of available online data (i.e. corporate websites); and (5) general contextual considerations (e.g. corporate identity, main suppliers, customers, and competitors). Some codes emerged beyond the initial template and thus the initial pre-defined thematic coding was combined with elements of open coding. The coding procedure was supported by the Nvivo 12 software.

Appreciation of corporate online references appeared to be a general pattern across the interviews. As one participant explained: “A good reference is a credibility builder. (...) It shows that they are known in the market for doing that, and also shows they have enough capacity to make that much product and to supply that demand". Representatives of small firms sometimes reported immense pressure when talking about supplier selection: "We put a lot of effort into that process. (...) We are an SME, so we do our due diligence. We score everyone [firms] we deal with".

When evaluating corporate online references, there were differences across the preferred level of information elaboration. Some advocated ample reference information: "where they've got the logos on their own doesn't...it shows me that, okay, they may do work with these people but I've got no idea as to what extent that is, so it doesn't give me much information", while others preferred to keep things simple: "we're bombarded with far too much information. So, there's got to be an element of keeping it simple and just providing the relevant information". Managers also appreciate the efforts it requires to gain references, especially more elaborated ones: “...testimonials are more difficult because again people might not want to have their name against it, yeah. And lots of clients as well request that you do not put their logo on your website."

Both corporate online references and WOM recommendations were deemed valuable in the supplier selection process: "I'm looking for a supplier then I will take or seek out recommendations and referrals from people. So, I'm a huge believer that third-party input or recommendation, testimonial can be very valuable in terms of the decision-making process." 
WOM recommendations, however, are not controllable and some SME managers reflected upon certain unpleasant experiences regarding the gap between their hopes and reality: "I found out from a current customer what they'd been saying about us. I thought we were getting on well and they liked us, and they were recommending us, but actually they were unrecommending us and saying what a bad job we're doing and yet they've been using us as a sounding board for work and for ideas. (...) it's interesting to hear that feedback that is completely the opposite to what my perception was."

\subsubsection{Focus groups}

Following the interviews and building on the initial managerial reflections, a focus group session was conducted involving 12 SME managers who were different from those interviewed earlier. Prior to joining the focus group session, managers registered online with their company credentials (their position, industry and company size). Participants convened around three tables with four managers at each table in the same room, with discussions taking place at their table but also at the level of the whole group. The focus groups were moderated by three members of the research staff (one staff member per table), and their extensive notes were eventually aggregated. The main author was in charge of addressing questions at each table as well as for the whole group. The focus group session lasted for approximately two hours. Similar to the interview setting, participants were encouraged to think of and share their first-hand experiences and perceptions regarding the supplier selection and references. Subsequent thematic analyses focused on different reference applications and contexts; perceived attractiveness in a B2B context (with special emphasis on the pre-selection stage); management of supplier selection processes; and potential similarities and differences in the approach of small versus large SMEs. Visual stimuli were often used to trigger discussions, and to ensure that interviewees understood the questions. The use of visual content was also important to test and fine-tune the format, content and protocol of the experimental phase.

Motivations for visiting the corporate website of potential suppliers included verifying their existence as well as confirming the veracity of what they said about themselves in person. Results confirmed the importance of differentiating between SMEs as a function of size. For instance, managers at medium-sized companies tended to emphasize 'tangible' evidence, such as testimonials, awards and qualifications, whereas managers at small companies tended to 
highlight the vital importance of the more 'intangible' WOM recommendations. Similarly, in the case of managers representing small firms, inter-personal and inter-organizational relationships were often blurred. For example, when talking about their collaborations, SME managers often used expressions like 'working with him/her', referring to the contact person at the company rather than the company itself, suggesting a particularly familial orientation. Along the same lines, similarly to the way one of the participants expressed his relation to his own firm by saying: "I am my business!", organizational partners were similarly personified.

In summary, the findings from the qualitative phase confirm that both corporate online references and WOM recommendations are used in supplier pre-selection. Also, when considering corporate online references, important differences emerged across the preferred level of information elaboration. The focus group was particularly interesting for assessing attitudinal differences between representatives of small versus medium-sized firms. Furthermore, the qualitative phase was helpful for obtaining a contextual understanding on reference management practices, and identifying potential covariates that may have an impact and thus should be accounted for during the experimental phase. Emerging covariates included reference attractiveness, supplier involvement, and skepticism towards references; with further details on each presented below.

\subsubsection{Hypothesis formulation}

A common pattern arose through the qualitative phase: while WOM recommendations were generally perceived as useful across companies of all sizes, managers coming from small firms tended to put an even stronger emphasis on them. For representatives of medium-sized firms, partner-selection processes were characteristically described as being somewhat more formalized (e.g. using an Excel sheet to compare options and incorporating the view of multiple colleagues in a discursive fashion), in which cases visually 'trackable' elaboration appeared particularly useful. These qualitative insights, in combination with the relevant SME literature, informed our hypothesis formulation.

It is important to recognize that small firms are often managed by their owners, and have a predominantly local/regional focus with a relatively limited share of the market. Their management styles tend to be less formalized in comparison to larger SMEs, as well as more personalized and relationship-focused (Fam \& Yang, 2006). The interview findings are 
consistent with previous research that suggests that in contrast to the transactional business model orientation that characterizes large SMEs, interactive relationship-based systems may be more advantageous for the small firms (Eggert \& Serdaroglu, 2011; Moore, Raymond, \& Hopkins, 2015). The strong preference for a personal touch appears to be a networking characteristic that is unique to small SMEs. For this reason, Ostgaard and Birley (1996) propose to set an upper size limit of 50 employees for small firms to study their network building initiatives, as beyond this level it is increasingly difficult to acquire a comprehensive understanding of personal connections that are especially important for these organizations.

The importance of WOM recommendations was highlighted repeatedly throughout the interviews and the focus group discussions. In fact, customers can assist the supplier preselection process greatly by providing WOM recommendations regarding suppliers with whom they like to be associated, which in turn can improve the perception and image of the potential supplier (Hansen, Samuelsen, \& Silseth, 2008). Small companies have a particularly strong reliance on WOM recommendations, partly due to the fact that collecting information through WOM incurs few, if any, direct costs (Stokes \& Lomax, 2002). Furthermore, several ownermanagers of small firms in Stage I reiterated the importance of WOM, following the logic of an informal insurance mechanism: "if they were good enough for them [a company they know], they will probably be good enough for us too". Based on relevant literature and the insights from the qualitative phase, we formulated our experimental research hypotheses as follows:

H1: An intention to initiate a business relationship with a supplier depends on the presence of a WOM recommendation and the customer's firm size, such as:

H1a: Small SMEs are more likely to initiate a business relationship after being exposed to a WOM recommendation versus not being exposed to a WOM recommendation.

H1b: The impact of WOM recommendation on initiating a business relationship is larger in the case of small SMEs, when compared to large SMEs.

Prior research suggests that higher degrees of information elaboration increases perceived importance (Homburg, Droll, \& Totzek, 2008) and strengthens one's ability to recall information, in turn enhancing the likelihood of behavioral action (Fern, Monroe, \& Avila, 1986). For instance, greater information elaboration has been linked with higher purchase 
intentions (Griffith, 2005). In our study, while there was no general agreement on the ideal level of information elaboration, some managers showed appreciation towards the time and effort invested into providing more elaborate corporate online references, which - in their opinion signaled greater commitment and higher satisfaction on behalf of the reference customer towards the supplier.

In addition to the potential variation in how different SMEs may react to the availability of WOM recommendation, it is important to consider the role of written references. When companies inquire about potential partners from different sources, their search is likely to result in a breadth of material that would emerge in combination rather than in silos. While there is enough evidence in the literature and insights from our qualitative findings to hypothesize differences emerging on the basis of the extent of elaboration, there is not enough support to establish directional hypotheses regarding customer firm size. Consequently, the following hypothesis is more exploratory in nature, and taking into account the size of the firm, we decided to formulate two sub-hypotheses, in order to investigate the hypothesized relationship both in the presence and absence of a WOM recommendation.

$\mathrm{H} 2$ : Both small and large SMEs prefer more elaborated written online reference (logo and testimonial combination over logo only), no matter whether WOM recommendation is present.

H2a: When exposed to a WOM recommendation, both small and large SMEs prefer more elaborated written online reference (logo-testimonial over logo only).

$\mathrm{H} 2 \mathrm{~b}$ : When there is no WOM recommendation, both small and large SMEs prefer more elaborated written online reference (logo-testimonial over logo only).

\subsection{Stage II - Experimental phase - Sampling and procedures}

In order to ensure that we consider all the hypothesized conditions, we deployed a $2 \times 2 \times 2$ experimental design. The three independent variables were: (1) the amount of information elaborated, as approximated by the 'logo only' versus the 'logo and testimonial' conditions; (2) the importance of WOM recommendation, as manipulated by its presence or absence, and (3) the size of the SME, differentiating between small SMEs (i.e. <50 employees) and large SMEs (50- 
250 employees). Our research design yielded 8 different combinations of experimental stimuli, as illustrated in Table 2.

\section{----- INSERT TABLE 2 AROUND HERE -----}

To guarantee adequate sample size a priori, we performed a power analysis using G*Power. Using an alpha of .05, for an $85 \%$ power to detect effects with a medium effect size of Cohen's $F$ $=.35$ in a $2 \times 2 \times 2$ between group design with 5 covariates, a minimum of 158 observations would be required (Cohen, 1988). Questionnaires were gathered from experienced managers employed by SMEs based in the United Kingdom, resulting in a database of 165 responses, which exceeds the minimum threshold of required observations. Applying also a 2 × 2 × 2 design, Lee and Aaker (2004) uses a sample of 163 for an experiment on information processing and persuasion. The applied design yielded on average of 20 participants per experimental group, a sample size similar to those used in other experimental studies (Casaló, Flavián, Guinalíu, \& Ekinci, 2015; Daryanto, Ruyter, Wetzels, \& Patterson, 2010; Ma, Yang, \& Mehdi, 2014; J. Wang \& Lee, 2006).

The present study focused on participants from SMEs in manufacturing and/or professional services, i.e. industries where B2B marketing characteristically plays a leading role. Participants were all employed full-time (or were the directors of their firm) and were recruited via an online survey panel. A market research company was engaged to assist with the experimental phase. As a prerequisite screener for participation, managers were required to have prior involvement and experience in supplier selection processes in their organization. Those with not sufficient experience automatically disqualified and were unable to proceed to later stages of the survey. In addition to the screening question that ensured adequate participant insight and experience, attention check questions were incorporated throughout the survey to ensure that respondents paid careful attention to all questions.

Initially, 641 managers at qualifying firms were contacted and the total number of responses received was 170 , yielding a response rate of $26.52 \%$. Five responses were further eliminated for issues such as 'speeding' (i.e. respondents who completed the survey in less than one third of the median lengths of the survey completion time) and/or 'straight-lining' (i.e. where $90 \%$ or more responses had the same value). The market research company employed for the current study is 
one of the major global players with dedicated key accounts specifically geared towards academic research. The online panel covered the whole United Kingdom with panel information available about firms (e.g. industry, size, location) as well as company contacts. While location was not made available as part of the survey, the market research firm confirmed a balanced approach in recruiting SMEs that represented firms from all over the United Kingdom.

The online panel was pre-targeted for firm size and industry (i.e. whether the firm is a UKbased manufacturer and/or provider of professional services), and additionally for full-time employees and directors of SMEs. Consequently, qualifying filter questions incorporated firm size, employment (requiring full-time employment or a director role), and influencer status (i.e. whether or not the respondent has been involved in or played an influencing role over decisions concerning supplier selection at their company). Similarly to Stage I, by implementing a twostep procedure of using firmographics (here pertaining to a combination of small- and mediumsized firms with a professional services or manufacturing background), along with the identification of key informants within the chosen firms (based on employment status, relevant experience and influence), our approach followed a common practice in B2B marketing (Anaza et al., 2019; J. L. Johnson et al., 2012; W.-L. Wang et al., 2017), where both organizational and managerial characteristics were taken into account.

The final sample consisted of 165 participants. Altogether, $45 \%$ of the participating managers worked for small as opposed to large SMEs, yielding a relatively balanced representation in terms of firm size. $11 \%$ have been employed at their current company for less than 2 years, $30 \%$ between 2 and 5 years, 29\% between 5 and 10 years, and 30\% for more than 10 years. $41 \%$ of the respondents were female. $32 \%$ of respondents worked for manufacturing firms, $63 \%$ worked for services form and $5 \%$ of respondents did not disclose the company's background. The ratio between manufacturing and services reflects on the overall primacy of services in the United

Kingdom. According to the official parliamentary report of the House of Commons Library (Library, 2018), service industries accounted for $72 \%$ of the total turnover in 2018.

\subsubsection{Measures}

The main measure approximating intention to initiate a business relationship with a supplier was adapted from the work of Luo (2001) on strategic intention to relationship building, and was modified slightly to reflect upon the qualitative findings of the current study. This measure 
yielded a total of 8 items (please see Table 3 for a comprehensive list of items for all measures, along with source, response scale and reliabilities). To ensure that our study was able to single out the impact of reference effectiveness to the greatest possible extent, we controlled for some key covariates that were identified in the qualitative phase and prior literature. In particular, evidence indicates that the impact of references on intention to initiate a business relationship with a potential supplier may be effected by reference attractiveness (Willemsen, Graus, \& Knijnenburg, 2016), supplier identity attractiveness (Marin \& Ruiz, 2007), individual involvement in the task of purchasing (Zaichkowsky, 1985), and overall skepticism towards promotional materials (Obermiller \& Spangenberg, 1998). In order to account for the effect these variables may exert on intention to engage in business relationships with potential suppliers, they were included in our model as covariates.

Reference attractiveness was adapted from Willemsen, Knijnenburg, Graus, VelterBremmers, and Fu (2011), yielding to a 4-item measure, with sample item: 'The presented references/partnerships are attractive overall'. Supplier identity attractiveness was measured based on a scale developed by (Marin \& Ruiz, 2007), which in our study resulted in a 4-item scale with sample item: 'Beagle Web Solutions is an attractive potential supplier'. Involvement in supplier selection was measured based on items from Zaichkowsky (1985), incorporating six statements such as: 'I collect information when it comes to supplier selection'. Finally, skepticism was measured using a 6-item scale originally developed by Obermiller and Spangenberg (1998), with items such as: 'We can rely on most of such references to gain truthful information'. Please refer to Table 3 for specific items for all measures. As the time respondents were employed in a company may affect the dependent variable, such that with time people tend to have more familiarity with their firm and more opportunities to accrue experience-based benefits (Dagger, Danaher, \& Gibbs, 2009), we also controlled for this factor in our model.

\section{----- INSERT TABLE 3 AROUND HERE -----}

In designing the questionnaire and in order to avoid a testing bias, the order of questions was determined in a way to allow managers a cognitive break. Consequently, questions related to task involvement (e.g. supplier selection practices) appeared in separate blocks from those that related to references (e.g. reference attractiveness). To avoid a selection bias - i.e. screening out 
participants who may not have the desired knowledge and / or required exposure to adequate firm size, industry or types of managerial experience, filter questions were employed at the beginning of the questionnaire reflecting key firmographic attributes (i.e. size, operations in the United Kingdom, and an industry background of either manufacturing or professional services), along with a suitable managerial profile. Content validity, referring to whether or not items and questions covered an extensive range of issues relevant to the research problem, was addressed during the qualitative phase by gaining initial feedback from a few managers on the survey tool prior to its launch. As a specific part of content validity, face validity associated with the questionnaire and the visual instruments were also investigated by asking two managers (whose surveys were not included in the overall data and were used exclusively for validation purposes) to complete the questionnaire, and obtain feedback on layout, style and wording. While no major changes appeared to be necessary at this stage, the wording of a few items has been amended and a few additional minor modifications were implemented in order to achieve further clarity.

Construct validity, referring to the extent to which the survey instrument measured the theoretical constructs of interest, was addressed by using already validated scales, incorporating some relevant modifications that were necessary to adjust to the context and / or to the information provided by the qualitative phase. The market research agency also performed a soft launch of the full questionnaire (20\% of the full sample size) that enabled us to check for any potential issues with the measurement items. For the internal reliability of constructs based on the final questionnaire, Cronbach alpha was calculated, and all our scales had the desired level or reliability, with the lowest Cronbach alpha $=.82$ (please refer to Table 3 for further details).

\subsubsection{Stimuli development}

For the purposes of the experimental stimuli, a digital marketing agency was identified as a potential supplier, given that most SME managers in the focus group found this example to be

most relevant (as opposed to stationery providers and other examples). The design of the experimental stimuli was informed by a combination of the literature as well as the results of the qualitative phased of the current study. To design the experimental stimuli, we used fictitious corporate brands. This is in line with the recommendations of Lee and Aaker (2004) emphasizing the risks of potential biases that may emerge when using information from real and existing organizations. These biases may include, but are not restricted to, tensions due to competition 
and the influence of reputable corporate brands. Research further suggests that using fictitious brands may increase the generalizability of experimental results, by reducing potential variance caused by the use of real brands (Chitturi, Raghunathan, \& Mahajan, 2008; Hoegg \& Alba, 2011; Lee \& Aaker, 2004). Similarly, throughout the phase of stimuli development, special emphasis was placed on obtaining logos that were neutral and arbitrary as opposed to others that may have entailed real-life connotations, in order to prevent the possibility of prior associations and corresponding bias. Two graphic designers supported the development of the stimuli (i.e. picture of website and the logo), one specializing in website design and the other in logos and similar visual representations. They both had ample SME experience in the United Kingdom.

A total set of 15 logos was developed for the present study (please see Appendix for further details) that were used during the qualitative phases, along with a few testimonials and five potential company names that were developed on the basis of earlier examples. All visuals and textual elements - such as tentative company names - were presented to the six SME managers participating in the study. These six managers were different from those participating in the interviews and focus group discussions. The aim of these discussions was to focus specifically on stimuli development and to obtain feedback. These interviews served as a pilot before moving to the 'main' stages of data collection. In line with earlier studies, managers were asked about the perceived attractiveness of the visuals, potential associations with brands, industries or other entities, and also about the feelings evoked by the forms, shapes and colors of the visuals (Labrecque \& Milne, 2012).

The name 'Beagle Web Solutions' emerged through the focus groups and was subsequently discussed further with the six SME managers who helped primarily in fine-tuning the stimuli for the experimental stage. While it was clear that a name was necessary to make the fictitious firm legitimate in the eyes of participants, it was decided that no further visual information (such as a corporate $\log$ ) should be displayed in relation to this hypothetical organization. Extensive notes were taken and follow up emails were saved. Drawing on these conversations, a final set of four logos and testimonials was selected, which were perceived as most neutral. Other stimuli features, including the picture of the website and testimonial examples were also finalized, prioritizing the identification of 'typical' and 'neutral' examples. 


\subsubsection{Experimental procedures}

Each participant was randomly assigned to one of four manipulations, as presented in Table 2. The manipulations included 1) being exposed only to logos with WOM present; 2) being exposed to logos and testimonials with WOM present; 3) being exposed only to logos with WOM absent; and 4) being exposed to logos and testimonials with WOM absent. In order to establish the two WOM conditions, participants were introduced to one of two scenarios. Scenario-based experiments have previously been applied to study B2B settings (Geiger, Dost, Schönhoff, \& Kleinaltenkamp, 2015). In particular, the group where WOM was absent was told that their reference selection process entailed a self-initiated search with no WOM recommendation. In contrast, the other group where WOM was present was told that their process was triggered by a WOM recommendation. Experimental scenarios emphasizing presence or absence of WOM recommendation were as follows:

(1) WOM recommendation present: Imagine that your company needs a new supplier,
more specifically a digital marketing agency, in order to increase online presence and
sales. You have found the website of Beagle Web Solutions initiated by a personal
recommendation (this person works neither for your company nor for Beagle Web
Solutions). Imagine you're looking at the Our Partners site of Beagle Web Solutions.
(2) WOM recommendation absent: Imagine your company needs a new supplier, more
specifically a digital marketing agency, in order to increase online presence and sales.
You have found the website of Beagle Web Solutions - this search was NOT initiated by a
personal recommendation. Imagine you're looking at the Our Partners site of Beagle Web
Solutions.

Following exposure to a given stimulus, participants rated their involvement in similar tasks related to supplier attractiveness. To give respondents a cognitive break and refresh their memory, they were shown the pictures of the corporate websites with the corporate references (i.e. logos or logos and testimonials) and were asked to answer the questions related to reference and supplier identity attractiveness, along with rating their skepticism towards references. 
Subsequently, they were evaluated on their intention to initiate a business relationship with the supplier. Finally, basic demographic and work-related questions were solicited.

\subsubsection{Stage II Results}

\section{On the impact of WOM presence and firm size on relationship intentions}

The 2 × 2 ANCOVA evaluating the effect of the presence versus absence of a WOM recommendation in combination with company size showed a significant interaction effect (F (1: 156) $=3.93, p=.049$, observed power $=.504)$, as illustrated in Figure 1. The covariates used included reference attractiveness, identity attractiveness of the supplier, typical involvement in supplier selection, overall skepticism towards references, and the time spent with the current company. The findings support hypothesis H1a, as small SMEs have shown significantly stronger intentions to initiate a business relationship after being exposed to a WOM recommendation $(\mathrm{M}=4.85, \mathrm{SE}=.11)$ versus not being exposed to one $(\mathrm{M}=4.57, \mathrm{SE}=.12, \mathrm{~F}$ $(1: 66)=2.90, p=.041$, observed power $=.389)$. In the case of large SMEs, the difference between the two conditions was not significant. In other words, large SMEs revealed comparable intentions to initiate a business relationship in the WOM recommendation $(\mathrm{M}=4.79, \mathrm{SE}=.11)$ as in the no WOM recommendation conditions $(\mathrm{M}=4.95, \mathrm{SE}=.10, \mathrm{~F}(1: 85)=.92, p=n s$, observed power $=.158)$.

In summary, according to the results, the role of WOM was different in the case of small versus large SMEs, with small SMEs relying more heavily on this particular signaling tool. Reference attractiveness $(\mathrm{F}(1: 156)=15.06, p<.001$, observed power $=.971$, overall skepticism towards references $(\mathrm{F}(1: 156)=9.82, p=.002$, observed power $=.876)$, and identity attractiveness of the supplier $(\mathrm{F}(1: 156)=7.24, p=.008$, observed power $=.762)$ were the strongest predictors for the intention to establish interaction with the supplier. In order to achieve a better understanding on how those factors may influence the supplier selection process, we entered those variables into a one sample t-test, evaluating their influence in the case of small and large SMEs, as observed by the distance of each observation from the mid-point of the scale (3.5). For both small and large SMEs, participants rated the reference as attractive $\left(\mathrm{M}_{\text {SmallSME }}=\right.$ 4.85, $\left.\mathrm{SD}=1.10, \mathrm{t}=10.46(72), \mathrm{p}<.001 ; \mathrm{M}_{\text {LargeSME }}=5.00, \mathrm{SD}=1.14, \mathrm{t}=13.83(91), \mathrm{p}<.001\right) ;$ were less skeptical towards referrals in general $\left(\mathrm{M}_{\text {SmallSME }}=3.09, \mathrm{SD}=1.00, \mathrm{t}=3.49(72), \mathrm{p}=\right.$ $\left..001 ; \mathrm{M}_{\text {LargeSME }}=2.95, \mathrm{SD}=1.08, \mathrm{t}=4.90(91), \mathrm{p}<.001\right)$, and found the identity of the supplier 
attractive $\left(\mathrm{M}_{\text {SmallSME }}=4.87, \mathrm{SD}=.95, \mathrm{t}=12.29(72), \mathrm{p}<.001 ; \mathrm{M}_{\text {LargeSME }}=5.07, \mathrm{SD}=1.01, \mathrm{t}=\right.$ $14.86(91), \mathrm{p}<.001)$. Interestingly, large SMEs were found to be slightly more positive in their evaluations, both in terms of reference and supplier attractiveness and also skepticism, although these results were not significant. The results showed no effect of gender or the industry the participants represented. The overall model demonstrates good predictive power with an Adjusted R Square of .56.

\section{----- INSERT FIGURE 1 AROUND HERE -----}

Figure 1 Interaction effect between WOM recommendation and company size on relationship intention

On the impact of reference type and customer firm size on relationship intentions after WOM recommendation

To understand the mechanisms behind supplier selection more fully, we explored how reference types in combination with company size may influence relationship intentions, at first with WOM present. The 2 x 2 ANCOVA assessing the effect of reference type and company size (and the same covariates as in the previous model testing H1) showed a significant interaction effect $(\mathrm{F}(1: 74)=4.92, p=.030$, observed power $=.590)$, partially supporting H2a, as illustrated in Figure 2. Employees of large SME's indicated marginally significantly stronger intentions to initiate a business relationship after being exposed to the logo and testimonial $(\mathrm{M}=4.91, \mathrm{SE}=$ $.13)$ versus the logo only condition $(\mathrm{M}=4.74, \mathrm{SE}=.13, \mathrm{~F}(1: 34)=2.22, p=.073$, observed power $=.304)$. However, in contrast to the hypothesis and our expectations, when exposed to a WOM recommendation, employees of small SMEs indicated significantly stronger intentions to initiate a business relationship after being exposed to the logo only $(\mathrm{M}=5.10, \mathrm{SE}=.13)$ versus the logo and testimonial condition $(\mathrm{M}=4.70, \mathrm{SE}=.14, \mathrm{~F}(1: 35)=3.10, p=.043$, observed power $=.403)$. This might be due to the fact that as a consequence of the WOM recommendation, small SME managers already know what they are looking for and thus do not seek further supporting evidence regarding the supplier.

Of the personal attractiveness measures and covariates, supplier identity attractiveness (F (1: $74=11.88, p=.001$, observed power $=.925)$, skepticism towards references $(\mathrm{F}(1: 74)=5.40$, $p=.023$, observed power $=.630)$, and length of time working at the company $(\mathrm{F}(1: 74)=5.21, p$ 
$=.025$, observed power $=.615$ ) were the strongest predictors for the intention to establish an interaction with the potential supplier.

Again, to gain a better understanding as to how these factors may influence the supplier selection process, we entered supplier identity attractiveness and skepticism into a one sample ttest, evaluating their influence in the case of small and large SMEs, as observed by the distance of each observation from the mid-point of the scale (3.5). For both small and large SMEs, participants were less skeptical towards references in general $\left(\mathrm{M}_{\text {SmallSME }}=3.15, \mathrm{SD}=1.09, \mathrm{t}=\right.$ 2.01 (39), $\left.\mathrm{p}=.05 ; \mathrm{M}_{\text {LargeSME }}=2.91, \mathrm{SD}=.94, \mathrm{t}=4.10(42), \mathrm{p}<.001\right)$, and found the identity of the supplier attractive $\left(M_{\text {SmallSME }}=4.92, \mathrm{SD}=.95, \mathrm{t}=9.43(39), \mathrm{p}<.001 ; \mathrm{M}_{\text {LargeSME }}=5.19, \mathrm{SD}\right.$ $=.97, \mathrm{t}=11.42(42), \mathrm{p}<.001)$. Similarly to the results above, a trend could be observed such that large SMEs seemed more positive in their evaluations, both in terms of supplier attractiveness and skepticism, although these findings were not significant. Considering the amount of time spent working for their company, 58\% of respondents indicated to have spent more than 5 years at their current firm. For small SMEs, the split was more balanced (52\% worked for more than 5 years) than for large SMEs (63\% worked for more than 5 years). Those working less than 5 years were more likely to initiate a relationship with a new supplier (M SmallSME $\left.=4.92, \mathrm{SD}=.96 ; \mathrm{M}_{\text {LargeSME }}=4.71, \mathrm{SD}=.94\right)$ when compared to those working for over 5 years $\left(\mathrm{M}_{\text {SmallSME }}=4.97, \mathrm{SD}=.70 ; \mathrm{M}_{\text {LargeSME }}=4.88, \mathrm{SD}=1.28\right)$. There were no significant associations between the dependent variable and gender. The overall model demonstrates a good predictive power with an Adjusted R Square of .68.

\section{----- INSERT FIGURE 2 AROUND HERE -----}

On the impact of reference type and firm size on relationship intentions without WOM recommendation

The procedures to test $\mathrm{H} 2 \mathrm{~b}$ were the same as in $\mathrm{H} 2 \mathrm{a}$, with the one difference being the absence of WOM recommendation. As expected, the interaction between customer firm's size and reference type was not significant $(\mathrm{F}(1: 73)=1.45, p=n s$, observed power $=.221)$. Consistently with $\mathrm{H} 2 \mathrm{~b}$, reference type appeared to be an important factor in influencing the intention to engage in a business relationship, with the logo and testimonial condition showing a 
significantly stronger effect on relationship intention $(\mathrm{M}=4.90, \mathrm{SE}=.13)$ than the logo only condition $(\mathrm{M}=4.59, \mathrm{SE}=.13, \mathrm{~F}(1: 75)=2.61, p=.055$, observed power $=.357)$.

Of the personal attractiveness measures and covariates, reference attractiveness $(\mathrm{F}(1: 73=$ $11.34, p=.001$, observed power $=.914)$, overall skepticism towards references $(\mathrm{F}(1: 73)=$ $6.07, p=.016$, observed power $=.682)$, and company size $(\mathrm{F}(1: 73=5.12, p=.027$, observed power $=.369)$ were the strongest predictors for the intention to establish a relationship with the potential supplier. The overall model demonstrates a good predictive power with an Adjusted R Square of .49. As illustrated in Figure 3, when no WOM recommendation was available, both small and large SMEs generally preferred the logo and testimonial over the logo only condition. While the difference between the two conditions was not significant in the case of small SMEs $(\mathrm{F}(1: 26)=.19, \mathrm{p}=n s)$, it was significant in the case of large SMEs. More specifically, our results revealed that logos together with testimonials $(\mathrm{M}=5.26, \mathrm{SE}=.17)$ as opposed to alone $(\mathrm{M}=4.65, \mathrm{SE}=.15, \mathrm{~F}(1: 42)=6.78, p=.013$, observed power $=.720)$ were more advantageous

- particularly in the case of large SMEs - in yielding significantly higher likelihoods of behavioral intention.

In order to gain a better understanding on how these factors may influence the supplier selection process, we entered reference attractiveness and skepticism into a one sample t-test, evaluating their influence in the case of small and large SMEs, as observed by the distance of each observation from the mid-point of the scale (3.5). For both small and large SMEs, participants were less skeptical towards referrals in general $\left(\mathrm{M}_{\text {SmallSME }}=3.02, \mathrm{SD}=.88, \mathrm{t}=3.12\right.$ (32), $\left.\mathrm{p}=.004 ; \mathrm{M}_{\text {LargeSME }}=2.98, \mathrm{SD}=1.19, \mathrm{t}=3.03(48), \mathrm{p}=.004\right)$, and found the referral attractive $\left(\mathrm{M}_{\text {SmallSME }}=4.75, \mathrm{SD}=1.13, \mathrm{t}=6.39(32), \mathrm{p}<.001 ; \mathrm{M}_{\text {LargeSME }}=4.93, \mathrm{SD}=1.08, \mathrm{t}=\right.$ 9.25 (48), $\mathrm{p}<.001)$. Interestingly, large SMEs tended to be more positive in their evaluations, both in terms of referral and skepticism, although the results were not significant.

\section{----- INSERT FIGURE 3 AROUND HERE -----}

\section{Discussion}

The purpose of the present study was to investigate the role of corporate online references in small- and medium-sized firms. Corporate online references are important tools to showcase a 
firm's collaboration portfolio (Barnes, Naudé, \& Michell, 2007), which in turn can be useful for managing business relationships (Aarikka-Stenroos \& Makkonen, 2014) and acquiring new client firms (Helm \& Salminen, 2010), by enhancing the firm's attractiveness as a reliable potential partner. Despite the general concensus about the benefits of referencing from the perspective of suppliers, research pursuing a more nuanced and empirically grounded perspective moving beyond the 'one size fits all' approach remains limited. For instance, variations are expected to emerge across small and large SMEs due to reseouce constraints, and being a relatively cost-efficient marketing tool (Akdeniz, Gonzalez-Padron, \& Calantone, 2010), corporate online references may be especially advantageous for firms with restricted marketing budgets, which is typically the case for SMEs.

Building on a set of focus group and one-to-one in-depth interviews conducted with representatives of small- and medium sized SMEs, the present study explored the preferential differences in reference information across small and large firms in terms of their impact on relationship intentions. Our findings demonstrate that both corporate online references and WOM recommendations exert a positive impact on the customer's intention to initiate a business relationship with the supplier, and in turn increase attractiveness in the partner selection phase. One size, however, did not fit all, and while large SMEs appeared to maintain their preference for more elaborated written references even in the presence of a WOM recommendation, in the case of small SMEs, less elaborated references, such as logos, appeared to be sufficient to evoke attractiveness, as long as the managers received a WOM recommendation as well. We acknowledge the underlying differences between small and large SMEs regarding their organizational structures and decision-making processes that focus on supplier selection, which can contribute to such preferential differences when it comes to business-to-business references.

Perhaps a less surprising, yet still valuable finding emerging from this study confirms the propositions made by Kim (2014) and Z. Wang and Kim (2017) such that positive WOM has a favourable effect on the development of buyer-supplier relationships. In our research, both small and large SMEs were more willing to initiate the business relationship when a WOM recommendation was present. Small SMEs, on the other hand, appeared to be satisfied with less elaborated online references (i.e. the logo only condition) when exposed to WOM to trigger a behavioral intention. Such reliance on WOM recommendations in small firms is in line with 
views regarding the primacy of personal relationships that is especially prevalent in small companies and family firms (Mustakallio, Autio, \& Zahra, 2008). While WOM recommendations represent a great tool to enhance partnering attractiveness, it is important to recognize that they are less controlled by firms when compared to other tools. In other words, while the strategic intent may be present overall, given its externally controlled nature, WOM recommendations normally become less strategically managed and coordinated (Villanueva, Yoo, \& Hanssens, 2008).

As a particularly important contribution to the literature, our study confirmed that a uniform and one size fits all approach does not necessarily hold in the case of B2B references. Nagy et al. (2017) highlight that due to their more flexible internal processes and power structures, large SMEs tend to cope more easily with challenges of accommodating to changes when compared to small firms, which are more likely to be locked into constraining relationships. Indeed, this study confirms the prevalence of different management styles between small and large SMEs, particularly in terms of preferences and processing structures related to referencing. Large SMEs maintained a preference for more elaborated references (regardless of the presence or absence of a WOM recommendation), which may reflect upon their more formalised and less personfocused operations in comparison to small SMEs (Fam \& Yang, 2006), and also upon the fact that the purchasing processes of large SMEs tend be more structured (and consequently less personal) when compared to those of smaller firms (Gadde \& Hakansson, 2001).

Unlike WOM recommendations, however, as highlighted by Noguti (2016), online references may play a more manageable yet similarly important role, given that they are able to produce longer-lasting positive effects. In fact, this study underlines the importance of corporate online references during the stage of relationship initiation, and as such provides the first empirical testing - to the best of our knowledge - in a B2B setting. Looking into the effectiveness of customer references in building organizational attractiveness has been an important gap in the extant literature, and this study addresses this gap. More specifically, we contribute to the discourse on organizational attractiveness in the supplier pre-selection processes (Hada et al., 2013; Hätönen \& Ruokonen, 2010) and reference utilization literature (Jalkala \& Salminen, 2010), according to which corporate online references provide an efficient way to 
leverage the supplier's current and previous client relationships in order to attract potential new customers.

Some key insights in terms of reference-related preferences are summarized in Table 4 . While there may of course be personal factors, such as skepticism, that influence the extent to which the customer would be encouraged by the corporate online reference to initiate a relationship, the size of the customer firm is an important corporate-level characteristic that appears to exert a notable influence. Besides firm size (Núñez-Pomar et al., 2016), the extent to which written references are elaborated and whether or not a WOM recommendation is present also matter. Although we may assume that the more written reference information the better, our study shows that this is not necessarily the case, and in fact has not been the case in small firms, at least in the presence of a personal recommendation.

The established differences between small and large SMEs regarding reference type effectiveness warrants further contemplation. Such differential might well be best understood in the context of the resource acquisition strategies of large companies. For instance, Zaefarian, Henneberg, and Naudé (2011) describe 'reference sales', i.e. sales primarily triggered by references, as one of the major resource acquisition strategies of medium-sized and large companies. Medium-sized companies often seek references with the intention to register and share them, and consequently their higher level of professional operationalization is reflected in the preference for the logo and testimonial combination, as opposed to WOM recommendations

The present study also contributes to the discussion on horizontal (i.e. capturing competitors and firms in other industries) and vertical connections (i.e. capturing customers and suppliers). In fact, references can accelerate the impact of horizontal connections on vertical connections. Hadjikhani and Thilenius (2005) found that the impact of horizontal connections strengthens the vertical connection. In a B2B referencing context, the reference creates a communication channel that enables information diffusion between the potential customer who is seeking a partnership with a new supplier, and the previous customer who has first-hand experience with the supplier being evaluated. Small and large SME customers differ in their preferences when it comes to reference information and in this sense, different combinations of references can further strengthen this horizontal connection. Importantly, there is also an option for vertical interaction, such that the potential customer can acquire more information from the previous customer about 
their collaboration with the supplier. The horizontal reference-based connection between the customers can strengthen relationship development efforts with the supplier vertically, as is the case between the potential customer and the supplier, by encouraging the potential customer to initiate the relationship with the supplier.

A particularly interesting and somewhat discrepant trend emerged on the basis of focus group discussions regarding information elaboration that should be noted, which was then corroborated during the experimental phase. During the focus groups entailing more abstract discussions about general preferences related to corporate online references, managers seemed to have placed heavier emphasis on gathering as much information as possible, in order to make an educated and well-informed decision about the supplier. In the experimental phase, however, where managers were exposed to concrete examples and scenarios of supplier firms, the earlier established 'more the merrier' approach to reference information seeking no longer prevailed, yielding to an emerging size differential. These results suggest that while learning about managerial preferences is important, the combination of abstract and practical forms of assessment may lead to a more comprehensive understanding.

\section{Conclusions}

\subsection{Theoretical contributions}

The current study advances our understanding on the partnering attractiveness of the firm (Ellegaard, 2012; Hüttinger et al., 2012; Mortensen \& Arlbjorn, 2012) and how they may be shaped by the use of corporate online references in SME contexts. In general, we demonstrated that small versus large SMEs appear to consider different factors when evaluating suppliers, in turn making certain types of attractiveness signals more efficient than others. Consequently, the present work advances the growing academic scholarship centred around B2B references that are focused, for instance, on actor engagement behaviour (Jaakkola \& Aarikka-Stenroos, 2018). Our work also contributes meaningfully to the literature on organizational attractiveness (Hald et al., 2009; Tanskanen \& Aminoff, 2015), supplier attractiveness specific to the pre-relationship stage (Olsen \& Ellram, 1997), and in more general to the emerging academic discourse concerning the role of B2B references (Jalkala \& Salminen, 2010). 
Our results indicated that more elaborated reference information (i.e. combination of logos and testimonials) tends to work more efficiently in creating initial appeal, which suggests that more reference information besides partner logos should be a rule of thumb when targeting large SMEs. Suppliers need to consider the size of the customers they typically seek to attract, and consequently, in B2B settings, the management of references should be part of the process of segmentation, targeting and positioning. Despite the general tendency towards favoring greater amounts of reference information, some companies, especially small SMEs, seem to find more concise reference information (i.e., logos only) sufficient as long as they received a WOM recommendation as well. While WOM recommendations cannot be controlled, suppliers could identify ways to encourage the creation of positive WOM to appeal to SME customers. This may include informal requests to share positive experiences when customers are especially satisfied, and this method may serve, for instance, as an efficient representation tool at relevant networking events.

It is important to note that skepticism towards references was incorporated, which captures a range of positive as well as negative lenience towards references on a general level. While corporate online references are almost exclusively positive, given the supplier's control over sharing them, potential clients may also assess employee-driven and other references as sources that may contain positive, negative, and/or mixed information about the supplier. Moreover, while in the present work we focused exclusively on client testimonials and partner logos, other types of references may also influence the decision processes in the supplier pre-selection phase. These references may entail consumer references, for instance, if the potential supplier serves individuals as well (such as in the case of removal companies), or employee references on corporate review sites. Although consumer references have limited power in signaling the existing network of a company and provide reputation benefits, they may nonetheless shed light on the variety of references that can influence the pre-selection phase.

A firm can play multiple referencing roles in their overall network, serving as a reference provider, supplier, and prospective customer. In this sense, potential role ambiguity in referencing deserves future research attention as well. Unlike in consumer settings where the consumer does not normally become a supplier, firms are often customers as well as suppliers, depending on the relationship. Based on the insights from the interviews and focus groups, 
despite the extensive use of others' references to inform the supplier pre-selection, the same does not necessarily hold in the other direction, and many firms do not pay careful enough attention to the management of their own references.

\subsection{Managerial implications}

Although managers cannot fully control the evolution of their firm's business network, they can indeed influence their attractiveness within the network. Corporate online references serve as important building blocks in this positioning and signaling endeavor, placing emphasis on their strategic management. Our interviews demonstrated an interesting discrepancy in this regard. Even though managers tended to incorporate references during their decision-making process associated with supplier pre-selection, they did not necessarily realize that references could enhance their firm's attractiveness. Relationship-specific investments in the creation of references should thus be made with a sound understanding of contextual elements, such as the typical size of targeted customers, their preferences of reference information elaboration, and expectations towards relational intensity corresponding to the industry.

Overall, acknowledging the importance of corporate online references and reviewing the firm's current referencing activities can be a useful exercise for any organization. Hence, as part of our managerial implications, we suggest a reference audit for firms considering the appeal for SMEs reaching beyond large customers. References should be managed on a strategic level, and this requires forward planning. Given that corporate online references are jointly created, in order to increase their ability to plan, suppliers could already express their reference-related preferences during the negotiation phase of collaborations, i.e. ask for prospective references at an early stage of the relationship. Customers should also consider providing references as potential non-financial benefits for the supplier that can be negotiated.

\subsection{Future research directions}

It would be interesting to examine how SME networking behaviors (Naudé, Zaefarian, Najafi Tavani, Neghabi, \& Zaefarian, 2014) and reference management practices may inform each 
other. While this study focused on supplier-selected corporate online references, customer firms and other organizations (e.g. governmental entities or charities) may also employ referencing on their websites to attract organizational partners and enhance their reputation. Therefore, further empirical investigation should extend the range of corporate online references and incorporate a more articulate network perspective between various types of organizations. In addition, although strong B2B brands are important to gain more references from customers (Bendixen, Bukasa, \& Abratt, 2004), little is known about the impact of references on B2B branding. Using hypothetical references in the current study may be seen as a limitation, yet it was necessary to avoid the influence of existing B2B brands in the experiment, as managers may already be familiar with these brands based on prior experiences. Future studies could address this branding aspect more fully, tapping into the discussion regarding references as an upstream marketing communication tool in the context of business networks.

As a limitation of the current study, we did not consider the potentially negative impact of non-positive references and mixed WOM on partnering attractiveness, which would be interesting to expand our understanding of corporate online reference management. Despite the variations in the extent to which written $\mathrm{B} 2 \mathrm{~B}$ references are elaborated and the emphasis they place on certain dimensions, it is important to recognize that these references are practically never negative. In most cases, the supplier has complete control over what appears on their website and therefore may filter out potentially negative remarks (Hada et al., 2013). There is, however, a wider variety of valence for consumer and employee references, in that critical and mixed opinions may appear that in turn can potentially influence the supplier pre-selection.

Addressing the question of referencing practices and attractiveness within dyads would be another exciting extension to the present study. Whether it comes to consumer or B2B references, the measurement of behavioral intentions relevant to attractiveness should be further refined. There are various ways behavioral intentions can be expressed, and this should be better reflected as part of the measures incorporated in future work that requires the further development of respective scales and measurement tools.

In the present study, no significant differences regarding relationship intentions across professional services and manufacturing firms were established, which supports some degree of generalizability. There are, however, limiting factors to generalizability as well, for instance 
regarding the industries not included in this study, such as retail of fast-moving consumer goods. Testing the results of this study on multiple, more extended samples would further improve generalizability and should be considered in follow-up work. Furthermore, cross-cultural contexts may entail additional differences in the use of digital information sources that may play a potential role during organizational partner selection. Therefore, future studies may consider countries beyond the United Kingdom, enhancing our knowledge of how to manage corporate online references across different cultural contexts. 


\section{References}

Aarikka-Stenroos, L. (2011). Reference communication and third actors in the initiation of business relationships. (PhD), Universrity of Turku, Finland.

Aarikka-Stenroos, L., \& Makkonen, H. S. (2014). Industrial buyers' use of references, word-ofmouth and reputation in complex buying situation. Journal of Business \& Industrial Marketing, 29, 344-352.

Aarikka-Stenroos, L., Sandberg, B., \& Lehtimäki, T. (2014). Networks for the commercialization of innovations: A review of how divergent network actors contribute. Industrial Marketing Management, 43, 365-381.

Adams, J. H., Khoja, F. M., \& Kauffman, R. (2012). An Empirical Study of Buyer-Supplier Relationships within Small Business Organizations. Journal of Small Business Management, 50, 20-40.

Akdeniz, M. B., Gonzalez-Padron, T., \& Calantone, R. J. (2010). An integrated marketing capability benchmarking approach to dealer performance through parametric and nonparametric analyses. Industrial Marketing Management, 39, 150-160.

Albadvi, A., \& Hosseini, M. (2011). Mapping B2B value exchange in marketing relationships: a systematic approach. Journal of Business \& Industrial Marketing, 26, 503-513.

Anaza, N. A., Kemp, E., Briggs, E., \& Borders, A. L. (2019). Tell me a story: The role of narrative transportation and the $\mathrm{C}$-suite in B2B advertising. Industrial Marketing Management.

Anderson, J. C., Håkansson, H., \& Johanson, J. (1994). Dyadic business relationships within a business network context. Journal of Marketing, 58, 1.

Baker, A. M., Donthu, N., \& Kumar, V. (2016). Investigating How Word-of-Mouth Conversations About Brands Influence Purchase and Retransmission Intentions. Journal of Marketing Research (JMR), 53, 225-239.

Barnes, B. R., Naudé, P., \& Michell, P. (2007). Perceptual gaps and similarities in buyer-seller dyadic relationships. Industrial Marketing Management, 36, 662-675.

Baxter, R. (2012). How can business buyers attract sellers' resources?: Empirical evidence for preferred customer treatment from suppliers. Industrial Marketing Management, 41, 1249-1258.

Belt, P., Harkonen, J., Mottonen, M., Kropsu-Vehkapera, H., \& Haapasalo, H. (2010). Technological uncertainty and verification and validation activities. International Journal of Innovation and Learning, 7, 223-243.

Bendixen, M., Bukasa, K. A., \& Abratt, R. (2004). Brand equity in the business-to-business market. Industrial Marketing Management, 33, 371-380.

Bi, S., Liu, Z., \& Usman, K. (2017). The influence of online information on investing decisions of reward-based crowdfunding. Journal of Business Research, 71, 10-18.

Braun, V., \& Clarke, V. (2006). Using thematic analysis in psychology. Qualitative Research in Psychology, 3, 77-101.

Braverman, J. (2008). Testimonials versus Informational Persuasive Messages: The Moderating Effect of Delivery Mode and Personal Involvement. Communication Research, 35, 666694.

Bridwell-Mitchell, E. N., \& Mezias, S. J. (2012). The Quest for Cognitive Legitimacy: Organizational Identity Crafting and Internal Stakeholder Support. Journal of Change Management, 12, 189-207. 
Brush, G. J. (2014). Dances with Wolves: Strategic Supplier Sourcing for Small Firm Innovation Enhancement. AMA Summer Educators' Conference Proceedings, 25, B-17-B-18.

Bryman, A., \& Burgess, R. G. (1994). Analyzing qualitative data. London: Routledge.

Casaló, L. V., Flavián, C., Guinalíu, M., \& Ekinci, Y. (2015). Do online hotel rating schemes influence booking behaviors? International Journal of Hospitality Management, 49, 28 36.

Cepeda, G., \& Vera, D. (2007). Dynamic capabilities and operational capabilities: A knowledge management perspective. Journal of Business Research, 60, 426-437.

Chitturi, R., Raghunathan, R., \& Mahajan, V. (2008). Delight by Design: The Role of Hedonic Versus Utilitarian Benefits. Journal of Marketing, 72, 48-63.

Chollet, B., Géraudel, M., \& Mothe, C. (2014). Generating Business Referrals for SMEs: The Contingent Value of CEOs' Social Capital. Journal of Small Business Management, 52, 79-101.

Claycomb, C., \& Frankwick, G. L. (2010). Buyers' perspectives of buyer-seller relationship development. Industrial Marketing Management, 39, 252-263.

Cohen, J. (1988). Small, medium and large F-values Statistical power analyses for the behavioural sciences (pp. 284-288). Hillsdale, NJ: Lawrence Erlbaum Associates.

Dagger, T. S., Danaher, P. J., \& Gibbs, B. J. (2009). How Often Versus How Long: The Interplay of Contact Frequency and Relationship Duration in Customer-Reported Service Relationship Strength. Journal of Service Research, 11, 371-388.

Daryanto, A., Ruyter, K., Wetzels, M., \& Patterson, P. (2010). Service firms and customer loyalty programs: a regulatory fit perspective of reward preferences in a health club setting. Journal of the Academy of Marketing Science, 38, 604-616.

de Boer, L., Labro, E., \& Morlacchi, P. (2001). A review of methods supporting supplier selection. European Journal of Purchasing \& Supply Management, 7, 75-89.

De Mattos, C., Burgess, T. F., \& Shaw, N. E. (2013). The impact of R\&D-specific factors on the attractiveness of small- and medium-sized enterprises as partners vis-à-vis alliance formation in large emerging economies. $R \& D$ Management, 43, 1-20.

Dobler, D. W., Burt, D. N., \& Starling, S. L. (2003). World Class Supply Management : The Key to Supply Chain Management. London: McGraw-Hill.

Dollinger, M. J., \& Kolchin, M. G. (1986). Purchasing and the Small Firm. American Journal of Small Business, 10, 33-45.

Duhan, S., Levy, M., \& Powell, P. (2001). Information systems strategies in knowledge-based SME's: the role of core competencies. European Journal of Information Systems, 10, 25.

Dwyer, F. R., Schurr, P. H., \& Oh, S. (1987). Developing Buyer-Seller Relationships. Journal of Marketing, 51, 11-27.

Eggert, A., \& Serdaroglu, M. (2011). Exploring the Impact of Sales Technology on Salesperson Performance: A Task-Base d Approach. Journal of Marketing Theory \& Practice, 19, 169-186.

Ellegaard, C. (2006). Small company purchasing: A research agenda. Journal of Purchasing \& Supply Management, 12, 272-283.

Ellegaard, C. (2012). Interpersonal attraction in buyer-supplier relationships: A cyclical model rooted in social psychology. Industrial Marketing Management, 41, 1219-1227.

Ellegaard, C., \& Ritter, T. (2006). Customer attraction and its purchasing potential. Paper presented at the IMP Conference, Milan, Italy. 
Ellis, S., \& Shpielberg, N. (2003). Organizational learning mechanisms and managers' perceived uncertainty. Human Relations, 56, 1233-1254.

Fam, K.-S., \& Yang, Z. (2006). Primary influences of environmental uncertainty on promotions budget allocation and performance: A cross-country study of retail advertisers. Journal of Business Research, 59, 259-267.

Felzensztein, C., Brodt, S. E., \& Gimmon, E. (2014). Do strategic marketing and social capital really matter in regional clusters? Lessons from an emerging economy of Latin America. Journal of Business Research, 67, 498-507.

Fern, E. F., Monroe, K. B., \& Avila, R. A. (1986). Effectiveness of Multiple Request Strategies: A Synthesis of Research Results. Journal of Marketing Research, 23, 144-152.

Fiocca, R. (1982). Account Portfolio Analysis for Strategy Development. Industrial Marketing Management, 11, 53-62.

Ford, D. (1980). The Development of Buyer-Seller Relationships in Industrial Markets. European Journal of Marketing, 14, 339.

Freel, M. (2000). External linkages and product innovation in small manufacturing firms. Entrepreneurship \& Regional Development, 12, 245-266.

Gadde, L.-E., \& Hakansson, H. (2001). Supply network strategies (1st ed.). Australia: John Wiley \& Sons.

Geiger, I., Dost, F., Schönhoff, A., \& Kleinaltenkamp, M. (2015). Which types of multi-stage marketing increase direct customers' willingness-to-pay? Evidence from a scenario-based experiment in a B2B setting. Industrial Marketing Management, 47, 175-189.

Gremler, D. D. (2004). The Critical Incident Technique in Service Research. Journal of Service Research, 7, 65-89.

Griffith, D. A. (2005). An examination of the influences of store layout in online retailing. Journal of Business Research, 58, 1391-1396.

Hada, M., Grewal, R., Lilien, \& Gary, L. (2013). Purchasing Managers' Perceived Bias in Supplier-Selected Referrals. Journal of Supply Chain Management, 49, 81-95.

Hadjikhani, A., \& Thilenius, P. (2005). The impact of horizontal and vertical connections on relationships' commitment and trust. Journal of Business \& Industrial Marketing, 20, 136-147.

Hald, K. S. (2012). The role of boundary spanners in the formation of customer attractiveness. Industrial Marketing Management, 41, 1228-1240.

Hald, K. S., Cordón, C., \& Vollmann, T. E. (2009). Towards an understanding of attraction in buyer-supplier relationships. Industrial Marketing Management, 38, 960-970.

Halinen, A. (2001). Relationship marketing in professional services : a study of agency-client dynamics in the advertising sector.

Hansen, H., Samuelsen, B. M., \& Silseth, P. R. (2008). Customer perceived value in B-t-B service relationships: Investigating the importance of corporate reputation. Industrial Marketing Management, 37, 206-217.

Hätönen, J., \& Ruokonen, M. (2010). Revising marketing strategies for supplier selection criteria: small firm approach from the information and communications industry. 25, 159167.

Helm, S., \& Salminen, R. T. (2010). Basking in reflected glory: Using customer reference relationships to build reputation in industrial markets. Industrial Marketing Management, 39, 737-743.

Herbig, P. (1994). Marketing Signals in Service Industries. Journal of Services Marketing, 8, 19. 
Herrera-Echeverri, H., Geleilate, J. G., Gaitan-Riaño, S., Haar, J., \& Soto-Echeverry, N. (2016). Export behavior and board independence in Colombian family firms: The reverse causality relationship. Journal of Business Research, 69, 2018-2029.

Hoegg, J., \& Alba, J. W. (2011). Seeing Is Believing (Too Much): The Influence of Product Form on Perceptions of Functional Performance. Journal of Product Innovation Management, 28, 346-359.

Homburg, C., Droll, M., \& Totzek, D. (2008). Customer Prioritization: Does It Pay Off, and How Should It Be Implemented? Journal of Marketing, 72, 110-130.

Hüttinger, L., Schiele, H., \& Schröer, D. (2014). Exploring the antecedents of preferential customer treatment by suppliers: A mixed methods approach. Supply Chain Management, 19, 1-48.

Hüttinger, L., Schiele, H., \& Veldman, J. (2012). The drivers of customer attractiveness, supplier satisfaction and preferred customer status: A literature review. Industrial Marketing Management, 41, 1194-1205.

Jaakkola, E., \& Aarikka-Stenroos, L. (2018). Customer referencing as business actor engagement behavior - Creating value in and beyond triadic settings. Industrial Marketing Management.

Jalkala, A., \& Salminen, R. T. (2009). Communicating customer references on industrial companies' Web sites. Industrial Marketing Management, 38, 825-837.

Jalkala, A., \& Salminen, R. T. (2010). Practices and functions of customer reference marketing-Leveraging customer references as marketing assets. Industrial Marketing Management, 39, 975-985.

Janeiro, P., Proença, I., \& Gonçalves, V. d. C. (2013). Open innovation: Factors explaining universities as service firm innovation sources. Journal of Business Research, 66, 20172023.

Johnson, J. L., Martin, K. D., \& Saini, A. (2012). The role of a firm's strategic orientation dimensions in determining market orientation. Industrial Marketing Management, 41, 715-724.

Johnson, M., \& Zinkhan, G. M. (1998). The impact of outcome, competency and affect on service referral. Journal of Services Marketing, 12, 397.

Kim, H. (2014). The role of WOM and dynamic capability in B2B transactions. Journal of Research in Interactive Marketing, 8, 84-101.

Koch, O. F., \& Benlian, A. (2015). Promotional Tactics for Online Viral Marketing Campaigns: How Scarcity and Personalization Affect Seed Stage Referrals. Journal of Interactive Marketing (Mergent, Inc.), 32, 37-52.

Kumar, V., Petersen, J. A., \& Leone, R. P. (2010). Driving Profitability by Encouraging Customer Referrals: Who, When, and How. Journal of Marketing, 74, 1-17.

Labrecque, L., \& Milne, G. (2012). Exciting red and competent blue: the importance of color in marketing. Journal of the Academy of Marketing Science, 40, 711-727.

Lee, A. Y., \& Aaker, J. L. (2004). Bringing the frame into focus: the influence of regulatory fit on processing fluency and persuasion. Journal of Personality and Social Psychology, 86, 205-218.

Levinson, S. C. (2003). Contextualizing 'Contextualization Cues'. In S. L. Eerdmans, C. L. Prevignano, \& P. J. Thibault (Eds.), Language and Interaction: Discussions with John J. Gumperz (pp. 31-39). Amsterdam, Netherlands: Benjamins. 
Levy, M., \& Powell, P. (1999). Assessing information systems strategy development frameworks in SMEs. Information \& Management, 36, 247.

Levy, S., \& Nebenzahl, I. (2008). The influence of product involvement on consumers' interactive processes in interactive television. Marketing Letters, 19, 65-77.

Library, H. o. C. (2018). Business Statistics. Retrieved from London, UK:

Lin, F.-J., \& Lin, Y.-H. (2016). The effect of network relationship on the performance of SMEs. Journal of Business Research, 69, 1780-1784.

Luo, Y. (2001). Equity sharing in international joint ventures: an empirical analysis of strategic and environmental determinants. Journal of International Management, 7, 31-58.

Ma, Z., Yang, Z., \& Mehdi, M. (2014). Consumer Adoption of New Products: Independent Versus Interdependent Self-Perspectives. Journal of Marketing, 78, 101-117.

Makkonen, H., Vuori, M., \& Puranen, M. (2016). Buyer attractiveness as a catalyst for buyersupplier relationship development. Industrial Marketing Management, 55, 156-168.

Mandják, T., Szalkai, Z., Neumann-Bódi, E., Magyar, M., \& Simon, J. (2015). Emerging relationships: How are they born? Industrial Marketing Management, 49, 32-41.

Marin, L., \& Ruiz, S. (2007). "I Need You Too!" Corporate Identity Attractiveness for Consumers and The Role of Social Responsibility. Journal of Business Ethics, 71, 245260.

Mason, R. B. (2008). Word of mouth as a promotional tool for turbulent markets. Journal of Marketing Communications, 14, 207-224.

Möller, K., \& Törrönen, P. (2003). Business suppliers' value creation potential A capabilitybased analysis. Industrial Marketing Management, 32, 109-118.

Moore, J. N., Raymond, M. A., \& Hopkins, C. D. (2015). Social Selling: A Comparison of Social Media Usage Across Process Stage, Markets, and Sales Job Functions. Journal of Marketing Theory \& Practice, 23, 1-20.

Morrissey, B., \& Pittaway, L. (2004). A study of procurement behaviour in small firms. Journal of Small Business and Enterprise Development, 11, 254-262.

Mortensen, M. (2012). Understanding attractiveness in business relationships - A complete literature review. Industrial Marketing Management, 41, 1206-1218.

Mortensen, M., \& Arlbjorn, J. (2012). Inter-organisational supplier development: the case of customer attractiveness and strategic fit. Supply Chain Management, 17, 152-171.

Mortensen, M., Freytag, P. V., \& Arlbjørn, J. S. (2008). Attractiveness in supply chains: a process and matureness perspective. International Journal of Physical Distribution \& Logistics Management, 38, 799-815.

Mustakallio, M., Autio, E., \& Zahra, S. A. (2008). Relational and Contractual Governance in Family Firms: Effects on Strategic Decision Making. In J. H. Astrachan, T. M. Pieper, \& P. Jaskiewicz (Eds.), Family Business (pp. 408-425): Elgar Reference Collection. International Library of Critical Writings on Business and Management, vol. 12. Cheltenham, U.K. and Northampton, Mass.: Elgar. (Reprinted from: [2002]).

Nagy, G., Megehee, C. M., Woodside, A. G., Laukkanen, T., Hirvonen, S., \& Reijonen, H. (2017). Achieving requisite variety in modeling firms' strategy heterogeneities: Explaining paradoxical firm-market performances. Industrial Marketing Management, 65, 100-128.

Narula, R. (2004). R\&D collaboration by SMEs: new opportunities and limitations in the face of globalisation. Technovation, 24, 153. 
Naudé, P., Zaefarian, G., Najafi Tavani, Z., Neghabi, S., \& Zaefarian, R. (2014). The influence of network effects on SME performance. Industrial Marketing Management, 43, 630641.

Noguti, V. (2016). Post language and user engagement in online content communities. European Journal of Marketing, 50, 695-723.

Nollet, J., Rebolledo, C., \& Popel, V. (2012). Becoming a preferred customer one step at a time. Industrial Marketing Management, 41, 1186-1193.

Núñez-Pomar, J., Prado-Gascó, V., Añó Sanz, V., Crespo Hervás, J., \& Calabuig Moreno, F. (2016). Does size matter? Entrepreneurial orientation and performance in Spanish sports firms. Journal of Business Research, 69, 5336-5341.

Obermiller, C., \& Spangenberg, E. R. (1998). Development of a Scale to Measure Consumer Skepticism Toward Advertising. Journal of Consumer Psychology (Lawrence Erlbaum Associates), 7, 159.

Olsen, R. F., \& Ellram, L. M. (1997). A Portfolio Approach to Supplier Relationships. Industrial Marketing Management, 26, 101-113.

Ostgaard, T. A., \& Birley, S. (1996). New venture growth and personal networks. Journal of Business Research, 36, 37-50.

Pansari, A., \& Kumar, V. (2017). Customer engagement: The construct, antecedents, and consequences. Journal of the Academy of Marketing Science, 45, 294-311.

Pardo, C., Henneberg, S. C., Mouzas, S., \& Naudë, P. (2006). Unpicking the meaning of value in key account management. European Journal of Marketing, 40, 1360-1374.

Patton, M. Q. (2002). Qualitative research and evaluation methods. Thousand Oaks: Sage.

Payne, A., Ballantyne, D., \& Christopher, M. (2005). A stakeholder approach to relationship marketing strategy: The development and use of the "six markets" model. European Journal of Marketing, 39, 855-871.

Pearson, J. N., \& Ellram, L. M. (1995). Supplier selection and evaluation in small versus large electronics firms. Journal of Small Business Management, 33, 53-65.

Pressey, A. D., Winklhofer, H. M., \& Tzokas, N. X. (2009). Purchasing practices in small- to medium-sized enterprises: An examination of strategic purchasing adoption, supplier evaluation and supplier capabilities. Journal of Purchasing \& Supply Management, 15, 214-226.

Pulles, N. J., Schiele, H., Veldman, J., \& Hüttinger, L. (2016). The impact of customer attractiveness and supplier satisfaction on becoming a preferred customer. Industrial Marketing Management, 54, 129-140.

Quayle, M. (2002). Purchasing in small firms. European Journal of Purchasing \& Supply Management, 8, 151.

Ramsay, J. (2001). The Resource Based Perspective, Rents, and Purchasing's Contribution to Sustainable Competitive Advantage. Journal of Supply Chain Management, 37, 38-47.

Ramsay, J., \& Wagner, B. A. (2009). Organisational Supplying Behaviour: Understanding supplier needs, wants and preferences. Journal of Purchasing \& Supply Management, 15, 127-138.

Rao, H. (1994). The social construction of reputation: Certification contests, legitimation, and the survival of organizations in the American automobile industry: 1895--1912. Strategic Management Journal, 15, 29-44. 
Redondo, Y. P., \& Fierro, J. J. C. (2007). Importance of company size in long-term orientation of supply function: an empirical research. Journal of Business \& Industrial Marketing, 22, 236-248.

Reimer, T., \& Benkenstein, M. (2016). When good WOM hurts and bad WOM gains: The effect of untrustworthy online reviews. Journal of Business Research, 69, 5993-6001.

Rodríguez, N. G., Pérez, J. S., \& Gutiérrez, J. A. T. (2008). Can a good organizational climate compensate for a lack of top management commitment to new product development? Journal of Business Research, 61, 118-131.

Salminen, R. T., \& Möller, K. (2006). Role of References in Business Marketing -- Towards a Normative Theory of Referencing. Journal of Business-to-Business Marketing, 13, 1-48.

Schiele, H., Calvi, R., \& Gibbert, M. (2012). Customer attractiveness, supplier satisfaction and preferred customer status: Introduction, definitions and an overarching framework. Industrial Marketing Management, 41, 1178-1185.

Schmitt, P., Skiera, B., \& Van den Bulte, C. (2011). Referral Programs and Customer Value. Journal of Marketing, 75, 46-59.

Schumacher, E. F. (2011). Small is beautiful: A study of economics as if people mattered. London, UK: Abacus Publishing.

Snehota, I., \& Håkansson, H. (1995). Developing relationships in business networks. London, UK: Routledge.

Srinivasan, S. (2004). Role of trust in e-business success. Information Management \& Computer Security, 12, 66-72.

Srivastava, D., \& Sharma, R. W. (2017). Developing a Model for Studying the Antecedents and Effects of Word of Mouth (WoM) and e-WoM Marketing Based on Literature Review. Jindal Journal of Business Research, 6, 25-43.

Stokes, D., \& Lomax, W. (2002). Taking control of word of mouth marketing: the case of an entrepreneurial hotelier. Journal of Small Business and Enterprise Development, 9, 349357.

Tanskanen, K., \& Aminoff, A. (2015). Buyer and supplier attractiveness in a strategic relationship-A dyadic multiple-case study. Industrial Marketing Management, 50, 128141.

Terho, H., \& Jalkala, A. (2017). Customer reference marketing: Conceptualization, measurement and link to selling performance. Industrial Marketing Management, 64, 175-186.

Thrassou, A., \& Vrontis, D. (2006). A Small Services Firm Marketing Communications Model for SME-Dominated Environments. Journal of Marketing Communications, 12, 183-202.

Tóth, Z., Henneberg, S. C., \& Naudé, P. (2015). Corporate online references: Conceptual Development and Empirical Investigation using Social Network Analysis. Paper presented at the 31st Annual IMP Conference, Kolding, Denmark.

Verdú-Jover, A. J., Lloréns-Montes, F. J., \& García-Morales, V. J. (2006). EnvironmentFlexibility Coalignment and Performance: An Analysis in Large versus Small Firms. Journal of Small Business Management, 44, 334-349.

Verhoef, P. C., Franses, P. H., \& Hoekstra, J. C. (2002). The Effect of Relational Constructs on Customer Referrals and Number of Services Purchased From a Multiservice Provider: Does Age of Relationship Matter? Journal of the Academy of Marketing Science, 30, 202-216. 
Villanueva, J., Yoo, S., \& Hanssens, D. M. (2008). The Impact of Marketing-Induced Versus Word-of-Mouth Customer Acquisition on Customer Equity Growth. Journal of Marketing Research (JMR), 45, 48-59.

Visentin, M., \& Scarpi, D. (2012). Determinants and mediators of the intention to upgrade the contract in buyer-seller relationships. Industrial Marketing Management, 41, 1133-1141.

Waller, D. S., Cusick, D. J., Matheson, H. D., \& Miller, M. K. (2001). Advertising agency activities used to attract new clients in Australia. Journal of Business \& Industrial Marketing, 16, 129.

Walter, A., Ritter, T., \& Gemüden, H. G. (2001). Value Creation in Buyer - Seller Relationships. Industrial Marketing Management, 30, 365-377.

Wang, J., \& Lee, A. Y. (2006). The Role of Regulatory Focus in Preference Construction. Journal of Marketing Research (JMR), 43, 28-38.

Wang, W.-L., Malthouse, E. C., Calder, B., \& Uzunoglu, E. (2017). B2B content marketing for professional services: In-person versus digital contacts. Industrial Marketing Management.

Wang, Z., \& Kim, H. G. (2017). Can social media marketing improve customer relationship capabilities and firm performance? Dynamic capability perspective. Journal of Interactive Marketing, 39, 15-26.

Wilkinson, I., Young, L., \& Freytag, P. V. (2005). Business mating: Who chooses and who gets chosen? Industrial Marketing Management, 34, 669-680.

Willemsen, M., Graus, M., \& Knijnenburg, B. (2016). Understanding the role of latent feature diversification on choice difficulty and satisfaction. User Modeling \& User-Adapted Interaction, 26, 347-389.

Willemsen, M., Knijnenburg, B., Graus, M., Velter-Bremmers, L. C. M., \& Fu, K. (2011). Using latent features diversification to reduce choice difficulty in recommendation lists. Paper presented at the RecSys'11 Workshop on Human Decision Making in Recommender Systems, Chicago, IL.

Wilson, D. T. (1995). An Integrated Model of Buyer-Seller Relationships. Journal of the Academy of Marketing Science, 23, 335-345.

Yoganathan, V., Osburg, V. S., \& Akhtar, P. (2018). Sensory stimulation for sensible consumption: Multisensory marketing for e-tailing of ethical brands. Journal of Business Research.

Zaefarian, G., Henneberg, S. C., \& Naudé, P. (2011). Resource acquisition strategies in business relationships. Industrial Marketing Management, 40, 862-874.

Zaichkowsky, J. L. (1985). Measuring the Involvement Construct. Journal of Consumer Research, 12, 341-352.

Zolkiewski, J., \& Turnbull, P. (2002). Do relationship portfolios and networks provide the key to successful relationship management? Journal of Business \& Industrial Marketing, 17, 575.

Zott, C., \& Huy, Q. N. (2007). How Entrepreneurs Use Symbolic Management to Acquire Resources. Administrative Science Quarterly, 52, 70-105. 
Table 1. Managers and sectors represented in the qualitative phase

\begin{tabular}{|l|l|l|l|}
\hline Managers participated in the focus groups \\
\hline & Industry & Sector & Size \\
\hline Manager 1 & Professional services & healthcare & medium \\
\hline Manager 2 & Professional services & finance & medium \\
\hline Manager 3 & Professional services & IT & small \\
\hline Manager 4 & Professional services & consultancy & small \\
\hline Manager 5 & Professional services & retail & small \\
\hline Manager 6 & Professional services & design & small \\
\hline Manager 7 & Professional services & event management & medium \\
\hline Manager 8 & Manufacturing & aerospace & medium \\
\hline Manager 9 & Manufacturing & $\begin{array}{l}\text { aerospace } \\
\text { different firm) }\end{array}$ & medium \\
\hline Manager 10 & Manufacturing & $\begin{array}{l}\text { construction } \\
\text { equipment }\end{array}$ & medium \\
\hline Manager 11 & Manufacturing & gearbox parts & small \\
\hline Manager 12 & Manufacturing & $\begin{array}{l}\text { furniture for retail } \\
\text { spaces }\end{array}$ & small \\
\hline Interviewed managers & one-to-one) & \multicolumn{2}{|l|}{} \\
\hline & Industry & Sector & Size \\
\hline Manager 1 & Manufacturing & aerospace & medium \\
\hline Manager 2 & Professional services & IT & small \\
\hline Manager 3 & Professional services & logistics & medium \\
\hline Manager 4 & Professional services & consultancy & small \\
\hline Manager 5 & Manufacturing & packaging & small \\
\hline Manager 6 & Manufacturing & telco (hardware) & medium \\
\hline Manager 7 & Professional services & architecture design & medium \\
\hline Manager 8 & Professional services & consultancy \& HR & small \\
\hline Manager 9 & confectionary & small \\
\hline Manager 10 & \multicolumn{2}{|l|}{} \\
\hline
\end{tabular}


Table 2. Illustration of the experimental design

\begin{tabular}{|l|c|c|c|c|}
\hline & \multicolumn{2}{|c|}{ Small SME } & \multicolumn{2}{c|}{ Large SME } \\
\hline WOM present & Logo only & $\begin{array}{c}\text { Logo \& } \\
\text { testimonial }\end{array}$ & Logo only & $\begin{array}{c}\text { Logo \& } \\
\text { testimonial }\end{array}$ \\
\hline WOM absent & Logo only & $\begin{array}{c}\text { Logo \& } \\
\text { testimonial }\end{array}$ & Logo only & $\begin{array}{c}\text { Logo \& } \\
\text { testimonial }\end{array}$ \\
\hline
\end{tabular}


Table 3. Measurement items of experimental variables

\begin{tabular}{|c|c|}
\hline \multicolumn{2}{|c|}{ Intention to initiate business relationship (Luo, 2001) } \\
\hline $\begin{array}{l}\text { "I'd intend to initiate further } \\
\text { communication with them" }\end{array}$ & $\begin{array}{l}\text { "I anticipate pursuing collaboration with } \\
\text { this Supplier" }\end{array}$ \\
\hline "I'd intend to call them on the phone" & $\begin{array}{l}\text { "I'd consider working with this Supplier to } \\
\text { lower my costs" }\end{array}$ \\
\hline "I'd intend $t$ & $\begin{array}{l}\text { "I'd consider working with this Supplier to } \\
\text { gain access to resources/skills our company } \\
\text { does not possess" }\end{array}$ \\
\hline "I'd intend to talk to them $i$ & $\begin{array}{l}\text { "I'd consider working with this Supplier to } \\
\text { seek a more competitive position at the } \\
\text { market" }\end{array}$ \\
\hline & $\alpha=.94$ \\
\hline \multicolumn{2}{|l|}{ Reference attractiveness (Willemsen et al. (2011) } \\
\hline $\begin{array}{l}\text { "Based on the attractiveness of presented } \\
\text { references/partnerships, I would give } \\
\text { Beagle a high rating" }\end{array}$ & $\begin{array}{l}\text { "The presented refert } \\
\text { seem to be convincing to } n\end{array}$ \\
\hline references/partnerships are & $\begin{array}{l}\text { "The list of references/pc } \\
\text { my preferences" }\end{array}$ \\
\hline & \\
\hline \multicolumn{2}{|c|}{ Identity attractiveness of the supplier (Marin \& Ruiz, 2007) } \\
\hline $\begin{array}{l}\text { "Beagle Web Solutions is an attractive } \\
\text { potential supplier". }\end{array}$ & $\begin{array}{l}\text { "Beagle Web Solut } \\
\text { would understand }\end{array}$ \\
\hline $\begin{array}{l}\text { "Beagle Web Solutions is a likeable } \\
\text { supplier because it seems to stand out from } \\
\text { their competitors". }\end{array}$ & $\begin{array}{l}\text { "My impression about Beagle Web } \\
\text { Solutions' identity is overall positive". }\end{array}$ \\
\hline & \\
\hline \multicolumn{2}{|c|}{ Involvement in supplier selection Zaichkowsky (1985) } \\
\hline $\begin{array}{l}\text { "I collect information when it comes to } \\
\text { supplier selection" }\end{array}$ & $\begin{array}{l}\text { eat deal of differences } \\
\text { liers" }\end{array}$ \\
\hline $\begin{array}{l}\text { "I explore what others say about potential } \\
\text { suppliers" }\end{array}$ & $\begin{array}{l}\text { "I have clear preferences when it comes to } \\
\text { supplier selection" }\end{array}$ \\
\hline $\begin{array}{l}\text { "I systematically compare different } \\
\text { characteristics of potential suppliers" }\end{array}$ & $\begin{array}{l}\text { "I greatly influence supplier selection } \\
\text { process in my company" }\end{array}$ \\
\hline & $(\alpha=$ \\
\hline \multicolumn{2}{|c|}{ Skepticism (Obermiller \& Spangenberg, 1998) } \\
\hline $\begin{array}{l}\text { "We can rely on most of such references to } \\
\text { gain truthful information" }\end{array}$ & $\begin{array}{l}\text { "I feel I've been accurately informed when } \\
\text { looking at such references" }\end{array}$ \\
\hline $\begin{array}{l}\text { "Such references are reliable sources of } \\
\text { information about the performance of } \\
\text { suppliers" }\end{array}$ & $\begin{array}{l}\text { "In general, such references present a true } \\
\text { picture of the supplier who owns that } \\
\text { website" }\end{array}$ \\
\hline $\begin{array}{l}\text { "Such references are reliable sources of } \\
\text { information about the relational qualities of } \\
\text { suppliers" }\end{array}$ & $\begin{array}{l}\text { "I believe most of such references provide } \\
\text { customers with essential information" }\end{array}$ \\
\hline & \\
\hline
\end{tabular}


Table 4. Illustration of $B 2 B$ reference preferences

\begin{tabular}{|l|c|c|}
\hline & Small SME & Large SME \\
\hline WOM present & $\begin{array}{c}\text { Less information elaboration } \\
\text { (Logo only) }\end{array}$ & $\begin{array}{c}\text { More information elaboration } \\
\text { (Logo \& testimonial) }\end{array}$ \\
\hline WOM absent & $\begin{array}{c}\text { More information elaboration } \\
\text { (Logo \& testimonial) }\end{array}$ & $\begin{array}{c}\text { More information elaboration } \\
\text { (Logo \& testimonial) }\end{array}$ \\
\hline
\end{tabular}

Figure 1: Interaction effect between WOM recommendation and the customer firm's size on intention to initiate the relationship

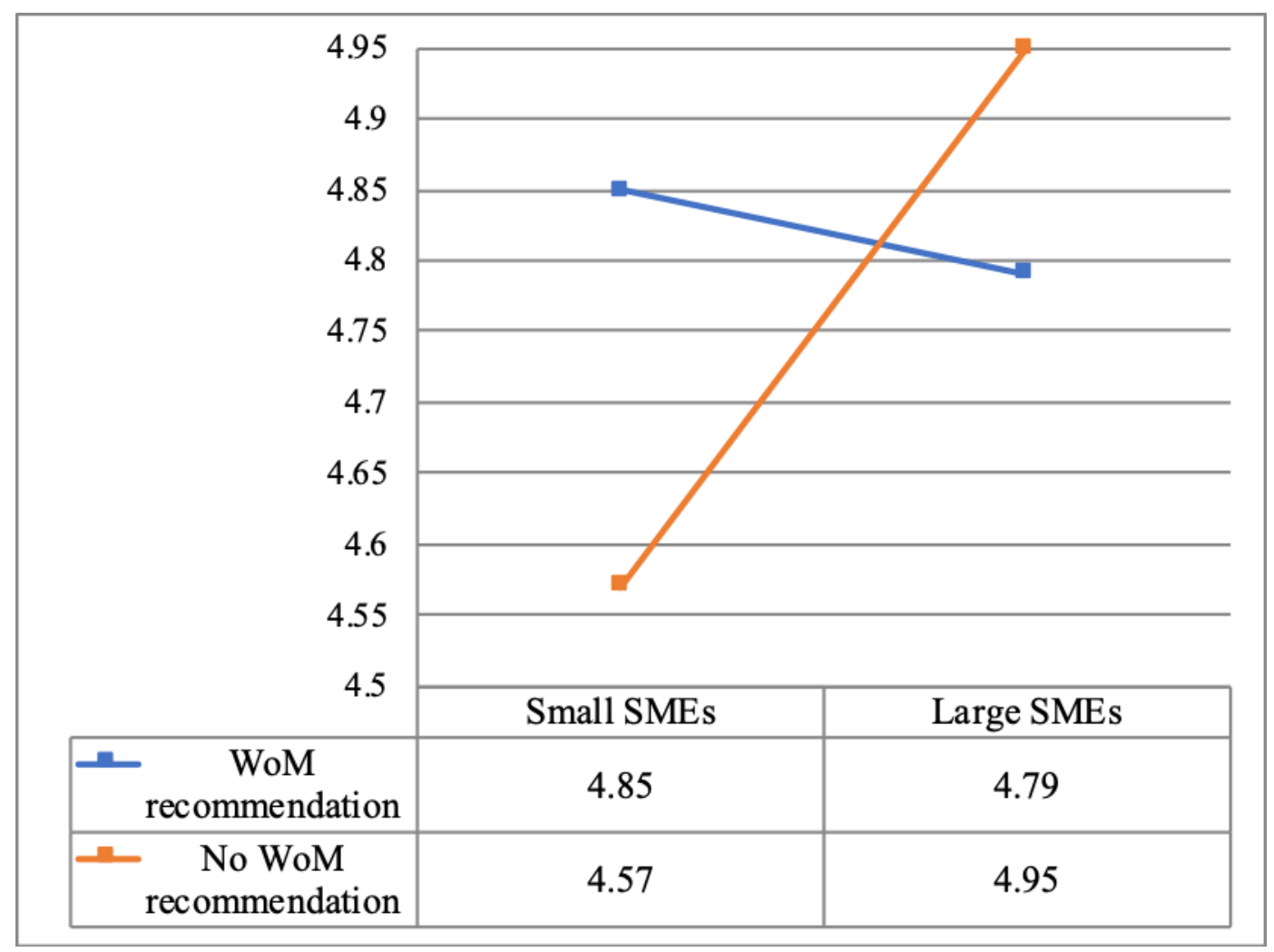


Figure 2: Interaction effect between reference type and the customer's firm size on the intention to initiate the relationship, when WOM recommendation is present

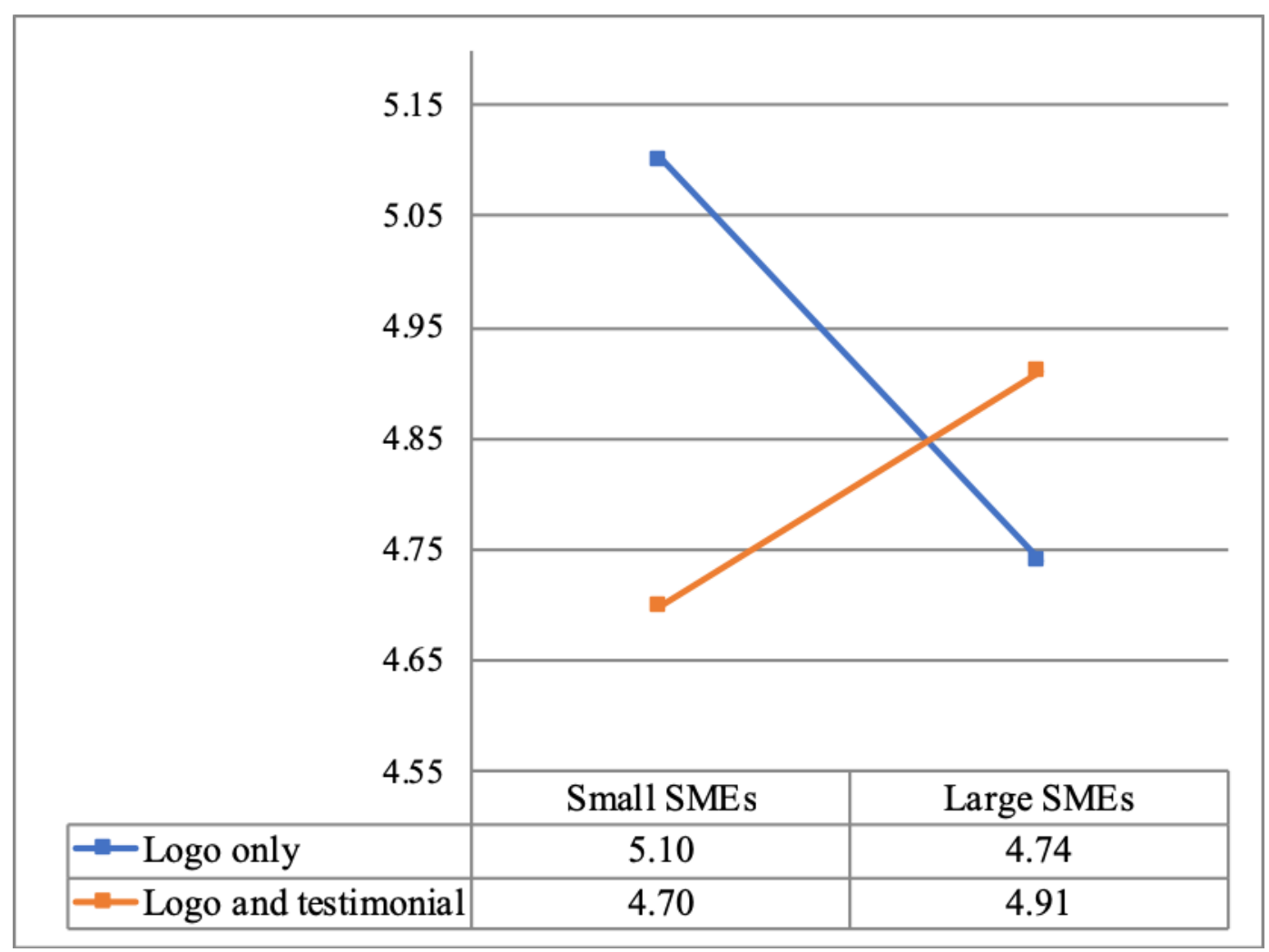


Figure 3: Interaction effect between reference type and firm size on the intention to initiate the relationship, when WOM recommendation is absent.

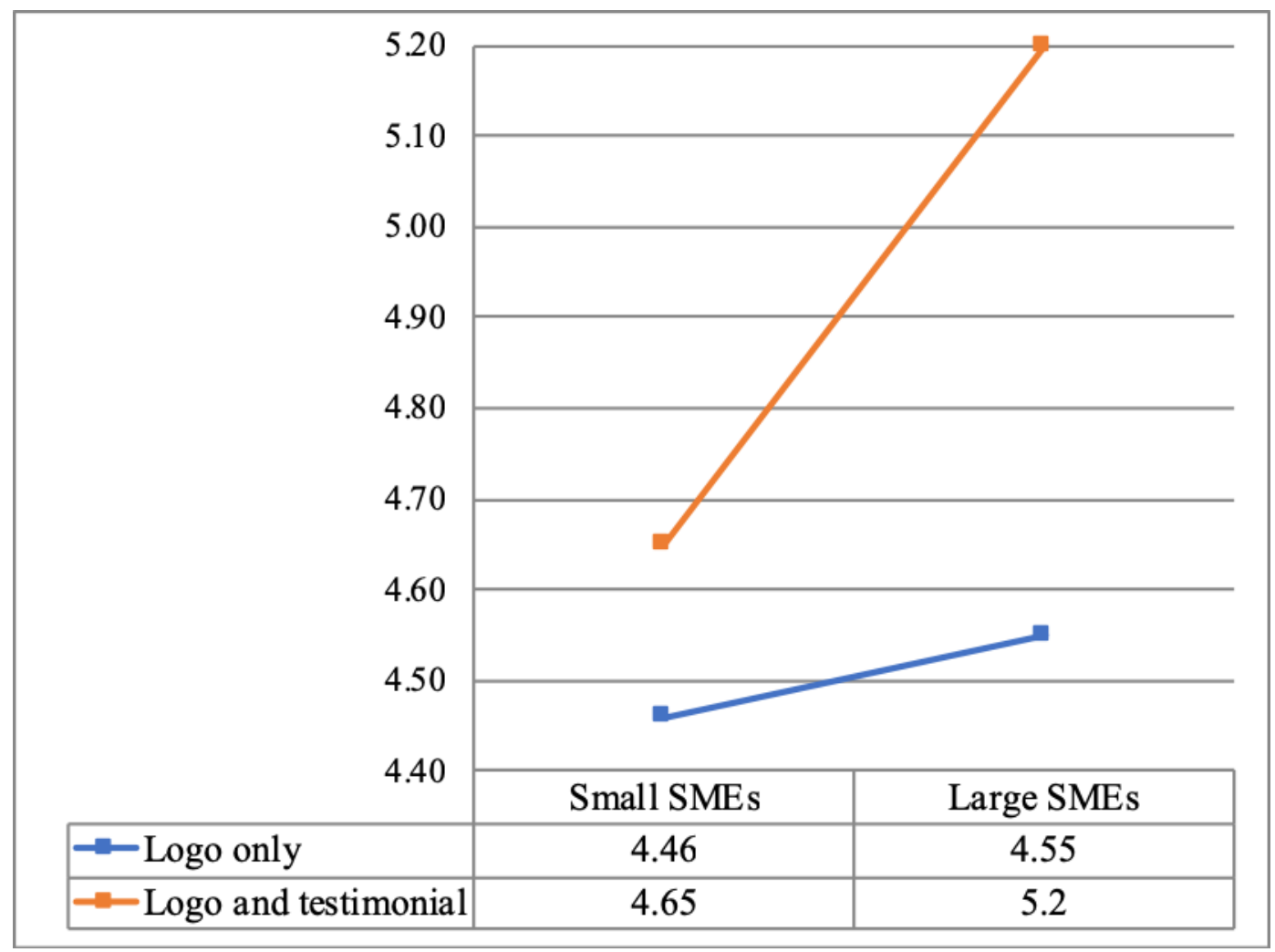

Appendix: Logos discussed as part of stimuli development

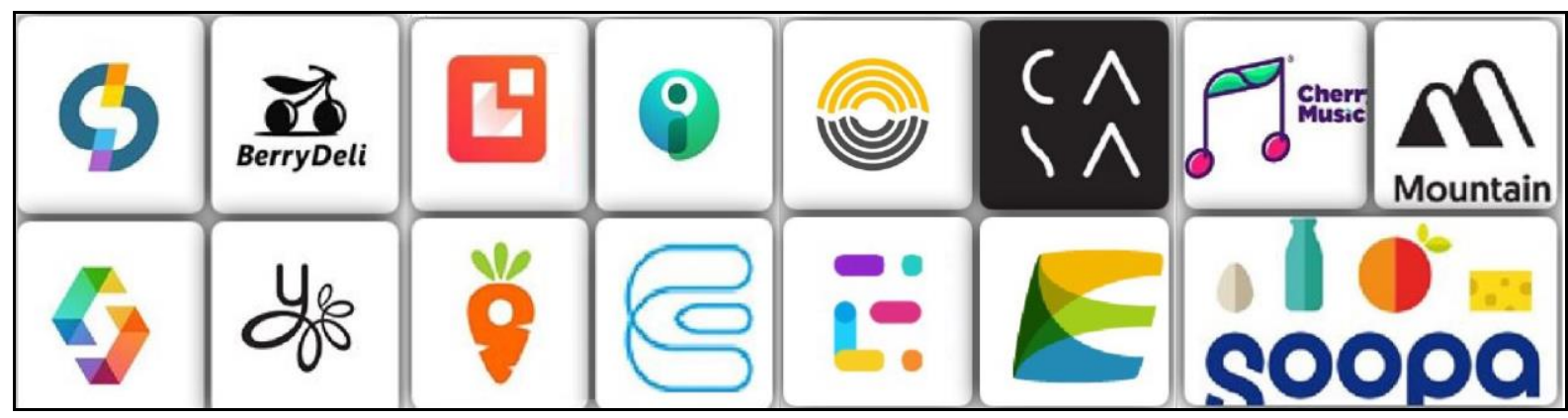

Note: potential company names that were discussed through stimuli development were Beagle, Kynesis, CentGrow, BusinessBit, and ActiveTopia. 